\title{
Lipidomic analysis of lactic acid bacteria strains by matrix-assisted laser desorption/ionization time-of-flight mass spectrometry
}

\author{
Justyna Walczak-Skierska, ${ }^{1}$ (1) Michał Złoch, ${ }^{1} \odot$ Katarzyna Pauter, ${ }^{1,2}$ Paweł Pomastowski, ${ }^{1 *}$ \\ and Bogusław Buszewski ${ }^{1,2}$ \\ ${ }^{1}$ Centre for Modern Interdisciplinary Technologies, Nicolaus Copernicus University in Toruń, Wileńska 4, 87-100 Toruń, Poland \\ ${ }^{2}$ Department of Environmental Chemistry and Bioanalytics, Faculty of Chemistry, Nicolaus Copernicus University in Toruń, Gagarina 7 , \\ 87-100 Toruń, Poland
}

\section{ABSTRACT}

Analysis by MALDI-TOF mass spectrometry and gas chromatography-mass spectrometry was used to characterize the lipid profile of 3 lactic acid bacteria strains. By gas chromatography coupled with mass spectrometry, 23 fatty acids were identified. Dominant acids were palmitic (C16:0), oleic (C18:1), and

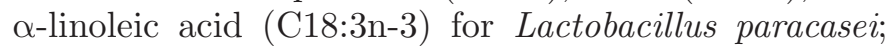
for Lactococcus lactis they were palmitic (C16:0), gondoic (C20:1), myristoleic (C14:1), and eicosadienoic acid (C20:2), respectively; and in the case of Lactobacillus curvatus were $\mathrm{C} 18: 1, \mathrm{C} 18: 2 \mathrm{n}-6$, and $\mathrm{C} 16: 0$, respectively. The effect of the medium on fatty acid composition was also determined. In addition, the fatty acid profile was also compared using MALDI MS analysis. The MALDI-TOF MS was used for qualitative analysis and identification of bacterial lipids. Phosphatidylglycerol, phosphatidylethanolamine, phosphatidylinositol, phosphatidylcholine, triacylglycerols, and ceramides were the most abundant species in lactic acid bacteria. One hundred different combinations of fatty acids in polar and nonpolar lipids have been identified, including 11 phospholipids (18 phosphatidylglycerol, 16 phosphatidylethanolamine, 10 phosphatidylinositol, 8 phosphatidylcholine, 4 lyso-phosphatidylethanolamine, 3 lyso-phosphatidylcholine, 3 phosphatidylserine, 1 lyso-phosphatidic acid, 1 lyso-phosphatidylglycerol, 1 lyso-phoshatidylinositol, and 1 phosphatidic acid), 23 triacylglycerols, 9 ceramides, and 2 sphingomyelin. The most abundant fatty acids identified were C16:0, C16:1, C18:0, and C18:3. Obtained lipid profiles allowed to distinguish the tested bacterial strains.

Key words: lactic acid bacteria, phospholipid, fatty acid, MALDI-TOF mass spectrometry

Received April 20, 2020

Accepted July 27, 2020.

*Corresponding author: p.pomastowski@umk.pl

\section{INTRODUCTION}

Throughout a relatively long period of time, whey has been underestimated and regarded only as a byproduct of cheese manufacture. At present, Greek yogurt is a rich source of whey (Bridge et al., 2019; Jørgensen et al., 2019). Nevertheless, whey is a highly valued nutritional product. The biological components of whey, such as $\beta$-LG, $\alpha$-LA, lactoferrin, and immunoglobulin, show several immunity-enhancing properties. Therefore, whey can be used as an antiviral and antibacterial agent (Layman et al., 2018). It is also used to treat various diseases, such as tuberculosis, as well as skin and gastrointestinal disorders, due to its healthy properties (Jeong et al., 2016).

The widely used starter cultures in the fermentation process are lactic acid bacteria (LAB), generally described as beneficial bacteria. Some LAB that produce only lactic acid during sugar fermentation are called homofermentative, whereas other types are heterofermenters that produce carbon dioxide, lactic acid, acetic acid, ethanol, and mannitol throughout the fermentation period. Lactic acid bacteria have been extensively used as starter cultures in the fermented food industry due to their metabolic activity on proteins, sugars, and lipids, thus contributing to food digestibility and preservation as well as the improvement of texture and sensory profile of the end product (Bottazzi, 1983). The use of LAB as a biopreservation agent and having probiotic properties demonstrates that they can be promising biological agents for food safety (Castillo Martinez et al., 2013).

Based on the currently available literature, probiotics can balance intestinal microbiota and thus regulate the proper functioning of the intestines and be effective in the prevention or treatment of gastrointestinal disorders such as intestinal diarrhea (Cano-Garrido et al., 2015). The most commonly applied bacterial species with probiotic properties include Lactobacillus (Lactobacillus acidophilus, Lactobacillus johnsonii, Lactobacillus casei, Lactobacillus rhamnosus, and Lactobacillus paracasei), and Bifidobacterium (Bifidobacterium bifidum, 
Bifidobacterium infantis) (Matarese et al., 2003). Other examples of health benefits promoted by probiotics delivered through dairy products are immunomodulatory (Piqué et al., 2019), reducing serum cholesterol (Albano et al., 2018), and antihypertensive (Daliri et al., 2018). In addition, it has been reported that LAB are used as a potential agent to minimize the contamination of mycotoxin and its toxicity (Peltonen et al., 2001).

Lactic acid bacteria are an important source of lipid compounds (Fahy et al., 2005). Lipids are an important building block of bacterial cell membranes, stabilize the cell membrane, and provide cell surface rigidity. They play a crucial role in the integrity of cell membranes, participate in metabolic and signaling pathways, and are energy and storage material (Wymann and Schneiter, 2008). Bacterial lipids not only play a passive role, as elements building the lipid bilayer, but also support cell functions such as targeted protein transport, DNA replication, and signal transduction. Changes in the composition of polar lipids affect the activity of cytoplasmic and periplasmic proteins associated with the adaptation of bacteria to the environment. Various chromatographic techniques, such as thin layer chromatography, liquid chromatography (LC), and GC, are used in lipids and fatty acid analysis (Wenk, 2005). Lipidomic studies increasingly use MS in targeted and nontargeted analysis, and coupled with LC (LC-MS; Liu et al., 2018; Chocholoušková et al., 2019; Peterka et al., 2020). The most commonly used techniques are electrospray ionization and MALDI. The MALDI-TOF MS technique is used in routine microbiological diagnostics to identify species of food-related microorganisms (Dušková et al., 2012; Król et al., 2018). In addition, attempts have been made to identify species of LAB both in clinical samples and in food (Buszewski et al., 2017; Król et al., 2018). The MALDI technique is also a promising tool in lipidomic research, in particular for imaging lipids from tissue preparations, as well as for the identification and classification of bacteria (Pulfer and Murphy, 2003).

Jacques Monod's research has shown that there is a relationship between the composition and concentration of nutrients contained in the medium and bacterial growth (Monod, 1949). The composition of the fatty acid profile of the cytoplasmic membrane depends on temperature, $\mathrm{pH}$, nutrient composition, solute concentration, water activity, and osmolarity. To change the profile of membrane fatty acids, an effective method is to modify the composition of the culture medium. In some cases, changing the medium causes the synthesis of UFA, cyclic fatty acids, and long-chain fatty acids, which improve LAB immunity (Fonseca et al., 2019).

The aim of the study was the molecular characterization of the lipid profile in selected LAB strains, isolated from whey. Comprehensive lipidomic analysis was performed using MALDI-TOF MS as a technique for rapid identification of lipids in whey (screening analysis). The lipid [phospholipids (PL) and triacylglycerols (TAG)] profile was compared in selected bacterial strains. The GC/MS analysis was performed to determine the fatty acid composition. In addition, the influence of the medium (composition) on the fatty acid profile of the tested bacterial strains was examined.

\section{MATERIALS AND METHODS}

\section{Chemicals}

Chemicals used were of a high purity grade and included the following: HPLC-grade water, methanol, acetonitrile, ethanol, chloroform, sodium chloride, sulfuric acid (VI), hexane, potassium carbonate, formic acid, trifluoroacetic acid (TFA), and FAME standard mixture (Sigma-Aldrich, Steinheim, Germany). Two different matrices were used in this study: $\alpha$-cyano4-hydroxycinnamic acid (HCCA) and 2,5-dihydroxybenzoic acid (DHB; both from Sigma-Aldrich). A mass standards kit for calibration was purchased from Sigma-Aldrich.

\section{Isolation of LAB Strains}

Lactic acid bacteria isolated from raw sweet whey (at $\mathrm{pH}=6.0$ ) were obtained from the local Dairy Factory in Drzycim and Kosów (Poland). Briefly, serial dilutions in peptone-physiological solution were prepared, and $0.1 \mathrm{~mL}$ of the $10^{-1}$ dilution was plated onto de Man, Rogosa, and Sharpe agar (MRS; Merck, Darmstadt, Germany), M17-agar medium (Sigma-Aldrich), and Milk Plate Count agar (Oxoid, Wesel, Germany) to selective isolation of a wide range of $\mathrm{LAB}$ species. All plates were incubated or cultivated at $37^{\circ} \mathrm{C}$ under aerobic conditions $\left(5 \% \mathrm{CO}_{2}\right)$, using an aerobic chamber (Memmert, Schwabach, Germany). After incubation for 24 to $48 \mathrm{~h}$, colonies were picked based on different colony morphologies and purified on the same combination of media by subculturing. Then, the pure cultures were stored at $4^{\circ} \mathrm{C}$ on MRS, M-17, or Milk Plate Count agar slants for further identification, whereas Cryobanks (Graso Biotech, Owidz, Poland) kept at $-80^{\circ} \mathrm{C}$ were used for long-term storage of strains selected for lipidomic studies.

\section{MALDI-TOF/MS Identification of Bacterial Isolates}

The identification process was performed based on the Bruker Guide to MALDI Sample Preparation (https:// www.bruker.com/fileadmin/user_upload/8-PDF-Docs/ 
Separations_MassSpectrometry/InstructionForUse/ IFU_268711_267615_226413_MALDI_Biotarget_48 _Rev1.pdf) with slight modification. The protocol included the use of HCCA $(10 \mathrm{mg} / \mathrm{mL})$ in a 50:48:2 acetonitrile:water:TFA matrix solution. A sample for MALDI-TOF/MS analysis was prepared following the ethanol/formic acid extraction procedure recommended by the manufacturer (Bruker Daltonik, Bremen, Germany). One to three individual bacterial colonies were collected filling a $1-\mu \mathrm{L}$ inoculation loop and suspended in $150 \mu \mathrm{L}$ of water. Subsequently, $450 \mu \mathrm{L}$ of absolute ethanol was added and mixed with the cell suspension. After centrifugation at $9,795 \times g, 20^{\circ} \mathrm{C}$, for $5 \mathrm{~min}$, the supernatant was discarded. The pellet was mixed with $70 \%$ formic acid (vol/vol), and an equal volume of acetonitrile was added. The mixture was centrifuged at $9,795 \times g, 20^{\circ} \mathrm{C}$, for $2 \mathrm{~min}$. One microliter of the supernatant was spotted onto a polished steel target plate and air-dried at room temperature. Each sample was overlaid. All spots were overlaid with 1 $\mu \mathrm{L}$ of MALDI matrix. Before the analyses, calibration was performed with the bacteria calibration standard (Bruker Bacterial Test Standard). Mass spectra of each sample (mass range 2 to $20 \mathrm{kDa}$ ) were analyzed using the MALDI BioTyper database (Bruker Daltonik) in the molecular weight range and the acceleration voltage in MALDI MS was $25 \mathrm{kV}$. All spectra were obtained by summing up the shot stages with a minimum laser power of $40 \%$. A score $>2.0$ indicates identification at the species level, whereas scores between 1.7 and 2.0 indicate genus-level identification. On the other hand, the score value under 1.7 shows no significant similarity between the unknown profile and the database. A unique main spectra (MSP) library was created using MALDI BioTyper Compass Explorer software. Dendrograms of identified strains were generated with the BioTyper MSP Dendrogram Creation Standard Method by matching obtained MSP to an MSP library and the closeness of the microorganisms' relationships to one another was reflected by an arbitrary distance level normalized to a maximum value of 1,000 according to guidelines provided by the manufacturer.

\section{Lipid Extraction from Bacteria}

Three different species, L. paracasei, Lactococcus lactis, and Lactobacillus curvatus, with potentially high probiotic properties (Fijan, 2014; Pavli et al., 2016) were used for further analysis. The lipid extractions were carried out according to Folch procedure with modifications (Folch et al., 1957). Bacterial pellets (approximately $60 \mathrm{mg}$ of each LAB strains) were mixed with $2 \mathrm{~mL}$ of chloroform/methanol (2:1, vol/ vol) mixture and ultrasonication for $10 \mathrm{~min}$ at room temperature (Shu et al., 2012), then $0.5 \mathrm{~mL}$ of sodium chloride $(0.05 \mathrm{M} \mathrm{NaCl})$. The mixture was shaken for 10 min on a rotary shaker $(200 \mathrm{rpm})$ and centrifuged at $2,415 \times g, 20^{\circ} \mathrm{C}$, for $15 \mathrm{~min}$. After centrifugation, the lower layer (chloroform) was removed and the process was repeated adding $0.5 \mathrm{~mL}$ of chloroform to the upper (methanol) phase. The lower phases were collected and dried under a stream of nitrogen. The extracted lipids were brought to $-20^{\circ} \mathrm{C}$ for future analysis.

\section{MALDI-TOF/MS Identification of Lipids}

The extracted lipids were dissolved in $0.5 \mathrm{~mL}$ of methanol. The 10-mg (DHB and HCCA) matrix was dissolved in $1 \mathrm{~mL}$ of the mixed solution (30:70, acetonitrile: $0.1 \%$ TFA in water). Two microliters of the extracted lipid samples was mixed with $2 \mu \mathrm{L}$ of either matrix, and this $1 \mu \mathrm{L}$ of mixture sample/matrix was applied to spot on an AnchorChip MALDI target plate (anchor diameter $800 \mu \mathrm{m}$; Bruker Daltonik GmbH, Bremen, Germany). The mass spectra were calibrated using the cesium triiodide cluster. Each sample was analyzed 3 times. A MALDI-TOF/TOF MS instrument equipped with a modified neodymium-doped yttrium aluminum garnet (Nd:YAG) laser (1-kHz Smartbeam-II, Bruker Daltonik) operating at the wavelength of $355 \mathrm{~nm}$ was used for all measurements. All spectra were acquired in reflector positive mode using an acceleration voltage of $25 \mathrm{kV}$ within a $\mathrm{m} / z$ range of 100 to 1,600 at $80 \%$ of laser power and global attenuator of $50 \%$. All mass spectra were acquired and processed using dedicated software, flexControl and flexAnalysis, respectively (both from Bruker Daltonik).

All of the lipid species were identified by using the LIPID MAPS online database (http://www.lipidmaps .org/; Fahy et al., 2007).

\section{S rDNA Identification of Selected LAB Strains}

For 3 selected LAB strains, additional identification was performed based on the sequencing of $16 \mathrm{~S}$ rDNA fragment according to protocol described in the work by Pomastowski et al. (2019). Genomic bacterial DNA was extracted from overnight cultures of selected LAB strains using the Bacterial Genomic Extraction GPB Mini Kit (GenoPlast Biochemicals, Rokocin, Poland), and amplification was performed of the $16 \mathrm{~S}$ rDNA region using universal bacterial primers $27 \mathrm{~F}$ (5'-AGAGTTTGATCMTGGCTCAG-3') and 1492R (5'-GGTTACCTTGTTACGACTT-3') and Taq DNA polymerase (Qiagen, Hilden, Germany). Subsequently, purified PCR products obtained were sequenced via the Sanger dideoxy method using the same primers, contigs were assembled via BioEdit Sequences Alignment Editor ver. 7.2.5 (Hall, 1999), and consensus sequences 
Table 1. Results of selected lactic acid bacteria strain identification based on the 16S rDNA sequencing

\begin{tabular}{|c|c|c|c|c|}
\hline Strain & $\begin{array}{l}\text { Related species from National Center } \\
\text { for Biotechnology Information } \\
\text { (accession number) }\end{array}$ & $\begin{array}{l}\text { Identities } \\
\quad(\%)\end{array}$ & Identify as & $\begin{array}{l}\text { Given } \\
\text { accession } \\
\text { number }\end{array}$ \\
\hline Lactococcus lactis & $\begin{array}{l}\text { L. lactis NBRC } 100933\left(\mathrm{NR} \_113960\right) \\
\text { L. lactis NCDO } 604 \text { (NR_040955) }\end{array}$ & $\begin{array}{l}100.00 \\
100.00\end{array}$ & L. lactis & MT706031 \\
\hline Lactobacillus paracasei & $\begin{array}{l}\text { L. paracasei R094 (NR_025880) } \\
\text { L. paracasei NBRC } 15889 \text { (NR_113337) }\end{array}$ & $\begin{array}{l}99.12 \\
99.05\end{array}$ & L. paracasei & MT706026 \\
\hline Lactobacillus curvatus & $\begin{array}{l}\text { L. paracasei } \text { ssp. tolerans NBRC } 15906 \\
\text { (NR_113823) } \\
\text { Lactobacillus zeae RIA } 482 \text { (NR_037122) } \\
\text { Lactobacillus casei NBRC } 15883 \text { (NR_113333) }\end{array}$ & $\begin{array}{l}97.17 \\
96.56 \\
96.48\end{array}$ & Lactobacillus sp. & MT706033 \\
\hline
\end{tabular}

were compared with references sequences in $\mathrm{RNA} / \mathrm{ITS}$ databases of the National Center for Biotechnology Information via the BLAST algorithm (https://blast.ncbi .nlm.nih.gov/Blast.cgi?PAGE_TYPE=BlastSearch). The DNA sequences determined in this study were submitted to GenBank, and accession numbers are given in Table 1.

GC-MS Analysis of Fatty Acids. The analysis of fatty acids from bacteria was performed on a $6890 \mathrm{~N}$ gas chromatograph (Agilent Technologies, Waldbronn, Germany) coupled with an Agilent 5975 Inert XL MSD mass spectrometer. A Zebron ZB-WAX $30 \mathrm{~m} \times 0.25$ $\mathrm{mm} \times 0.25 \mu \mathrm{m}$ (Phenomenex, Torrance, CA) capillary column was used. The oven temperature program was as follows: initially $60^{\circ} \mathrm{C}$ held for $2 \mathrm{~min}$, then increased at $13^{\circ} \mathrm{C} / \mathrm{min}$ to $150^{\circ} \mathrm{C}$, and then increased at $2^{\circ} \mathrm{C} / \mathrm{min}$ to $230^{\circ} \mathrm{C}$ and held for $6 \mathrm{~min}$. The temperature of the splitless injector was $240^{\circ} \mathrm{C}$. The MS analyses were carried out in full-scan mode, with scan mass range of $\mathrm{m} / \mathrm{z}$ 35 to 450 . The spectra were collected at electron ionization of $70 \mathrm{eV}$, and both ion source and line transfer temperatures were set at $200^{\circ} \mathrm{C}$. The acquisition of chromatographic data was performed by using the Chemstation 3 software (Agilent). The FAME were identified by comparison of retention times and MS spectra with the reference substances. Significant differences among the investigated groups in terms of the content of $\Sigma$ SFA, $\Sigma$ MUFA, and $\Sigma$ PUFA were analyzed by one-way ANOVA with Fisher's least significant difference test. The calculation was performed on Statistica software (Statistica ver. 7, StatSoft, Tulsa, OK).

Derivatization of Fatty Acids. Fatty acids were methylated according to the modified procedure described by Christie (Christie, 1984). Bacterial pellets were dissolved in $1 \mathrm{~mL}$ of pure methanol, adding $1 \mathrm{~mL}$ of $1 \%$ solution of sulfuric acid (VI) in methanol, and the test tubes were placed in a water bath at $80^{\circ} \mathrm{C}$ for $20 \mathrm{~min}$. After cooling the tubes, $1 \mathrm{~mL}$ of $6 \% \mathrm{NaCl}$ was added. The samples were mixed and the mixture was extracted 3 times with $1-\mathrm{mL}$ portions of hexane. All hexane extracts were connected and washed with
$1.5 \mathrm{~mL}$ of $4 \%$ potassium carbonate solution and subsequently dried. Dried extracts were concentrated by evaporation of the solvent under gentle nitrogen stream (low gas pressure 3-4 bar). The samples were dissolved in methanol for MALDI MS and GC/MS analysis. Each fraction was analyzed 3 times.

\section{RESULTS AND DISCUSSION}

\section{MALDI-TOF/MS Identification of Bacterial Isolates}

The MALDI-TOF/MS analysis allowed us to obtain MS spectra for the tested bacterial strains. Figure 1 shows examples of MS spectra for 2 selected bacterial strains. Bacterial strains derived from whey were identified using the MALDI BioTyper platform (Table 2 ). Analyzing raw spectra, $73 \%$ of the isolates were classified at the species level as high confidence identification (>1.999). However, only 2 strains, W10 and W15, associated with $L$. paracasei were identified at the very high confidence level (2.300-3.000). Twenty-seven percent of isolates were identified at the low confidence level (1.700-1.999). For one strain, W29, no reliable identification was obtained. Point values identified as L. paracasei were around $53 \%$, whereas L. lactis was $27 \%$. In the case of spectra obtained in the MSP mode, the percentage of identified strains at a high confidence level was lower compared with raw spectra $(52 \%)$. The number of no reliable identifications increased from 1 to 2 strains; in addition to the W29 isolate, there was also W11. All $L$. paracasei strains were identified with a high confidence level $(>1.999)$ for both raw and MSP spectra (Table 2).

Figure 2 shows the MSP dendrogram, which shows phyloproteomic relationships between isolates. The dendrogram revealed the presence of 12 groups of closely related bacterial species (A-L). Two large clusters were distinguished: L. paracasei (A) and L. lactis (L). Unidentified isolates W11 and W29 were also placed on a phyloproteomic tree near related strains. Both isolates were identified in the same cluster $(\mathrm{J})$. 


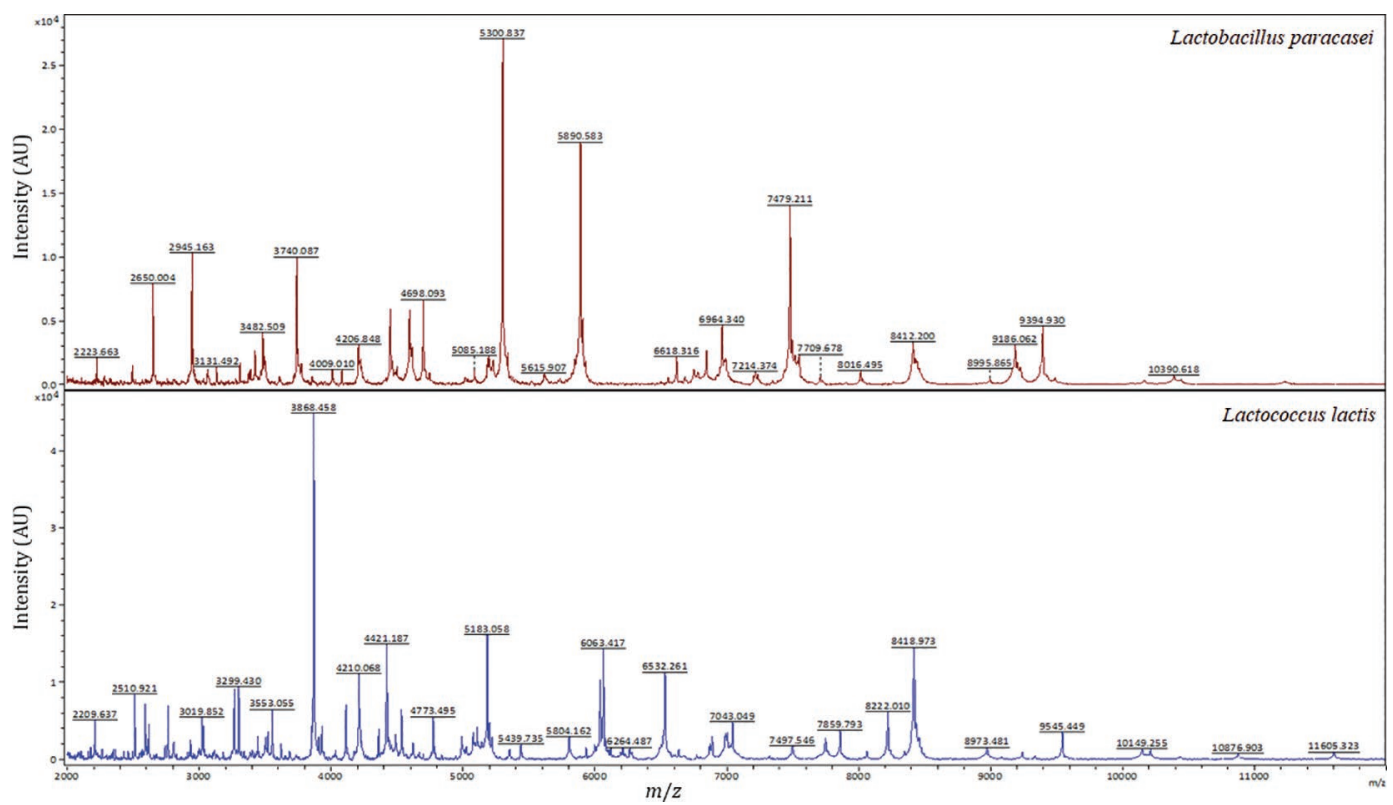

Figure 1. Comparison of MALDI-TOF MS profiles of Lactobacillus paracasei and Lactococcus lactis. $\mathrm{m} / z=\mathrm{mass-to-charge} \mathrm{ratio}$; AU $=$ arbitrary units.

Additional DNA-based identification of selected LAB strains, L. lactis, Lactobacillus paracasei, and L. curvatus, confirmed results of MALDI identification in the case of L. lactis and L. paracasei, whereas the case of L. curvatus sequencing of $16 \mathrm{~S}$ rDNA only allowed for reliable genus classification as Lactobacillus sp. (Table 1). Given the articles describing the higher success rate of lactic bacteria identification for MALDI compared with PCR technique (e.g., Dušková et al., 2012), in the case of a $L$. curvatus strain we accepted the result of MALDI identification as sufficient for species determination because comparison with a reference database (MALDI BioTyper 3.0) was unambiguous.

\section{Fatty Acid Profile by GC/MS}

The GC/MS analysis was performed to comparison of fatty acid composition in 3 bacterial strains. Additionally, the effect of medium (MRS and M17 agar medium) on the bacterial profile of fatty acids was also studied. Fatty acids were extracted from $L$. paracasei, L. lactis, and L. curvatus. By GC/MS analysis 23 fatty acids were identified having from 8 to 23 carbon atoms, and from 0 to 3 double bonds (Figure 3 ). The conducted studies showed differences in the content of fatty acids between L. paracasei, L. lactis, and $L$. curvatus. Nineteen fatty acids were identified in $L$. paracase $i$ strain. Three dominant compounds were identified: palmitic acid (C16:0), oleic acid (C18:1), and $\alpha$-linoleic acid (C18:3n-3), whose relative concentration was $35.77 \pm 2.54,22.00 \pm 3.24$, and $12.48 \pm 1.04$ (\% of total fatty acids), respectively (Figure 3 ). In the case of strain $L$. lactis the following fatty acids were identified: C8:0, C10:0, C11:0, C12:0, C14:0, C14:1, C15:0, C16:0, C16:1, C17:0, C18:0, C18:1, C18:2n-6, C18:3n-6, C18: 3n-3, C20:1, C20:2, C20:3n-6, C22:1, and C23:0. The highest content was observed for palmitic acid (C16:0), gondoic acid (C20:1), myristoleic acid (C14:1), and eicosadienoic acid (C20:2). In the case of L. curvatus, only 12 fatty acids were identified. The dominant acids were C18:1, C18:2n-6, and C16:0, respectively. In each of bacterial strains, a similar value of C8:0, C16:1, C18:0, and C22:1 fatty acids was observed. To illustrate the differences between groups of fatty acids, Figure 3 presents the histogram of the average and normalized values for 3 bacterial strains. For SFA, significantly higher intensities were noted for $L$. paracasei (MRS and M17 medium) compared with L. lactis and L. curvatus. In the case of MUFA, significantly higher values were found for L. lactis and L. curvatus compared with $L$. paracasei, for which there were no statistically significant differences between MRS and M17 medium. In the case of PUFA, significantly higher intensity values were recorded for $L$. curvatus (MRS and M17 medium) compared with $L$. paracasei and L. lactis, between which there were no statistically significant differences. It was observed that $L$. paracasei and L. lactis were similar in the overall content of PUFA, whereas L. lactis and $L$. curvatus were similar in the overall content of MUFA. In the case of $L$. paracasei, more than $60 \%$ of total fatty acids, were constituted SFA. It can also be seen that the overall content of SFA and MUFA were very simi- 
lar in the case of L. curvatus (Figure 3). Lactobacillus paracasei contained the highest content of palmitic acid (C16:0) compared with the other 2 strains. In addition, only arachidic acid (C20:0) and cis-13,16-docosadienoic acid (C22:2) were identified for this strain. It should be mentioned that a high content of $\alpha$-linolenic acid (C18:3n-3) was observed (average value 11.26 \pm 1.54 ), which belongs to the n- 3 family of acids and is part of a healthy and balanced diet. In the case of L. lactis, the largest number of n-3 (C18:3n-3) and n-6 (C18:2n -6 , C18:3n-6, C20:3n-6) acids were identified. Linoleic acid and $\alpha$-linolenic acid are considered essential fatty acids because the human body cannot synthesize them. These fatty acids are precursors of eicosapentaenoic acid and docosahexaenoic acid, which play a key role in regulating homeostasis (Komprda, 2012). However, L. curvatus contained the highest value of linoleic acid (C18:2n-6).

The obtained fatty acid profiles for $L$. paracacei, $L$. lactis, and $L$. curvatus are characteristic of LAB biomass (Guerzoni et al., 2001; Vieira et al., 2015; Kiss et al., 2019). Lactic acid bacteria have the ability to synthesize fatty acids with a carbon chain length from 12 to 23 carbon atoms. The results of the analysis of fatty

Table 2. MALDI-TOF MS identification results from raw samples (primary identification) and main spectra (MSP) library (second identification)

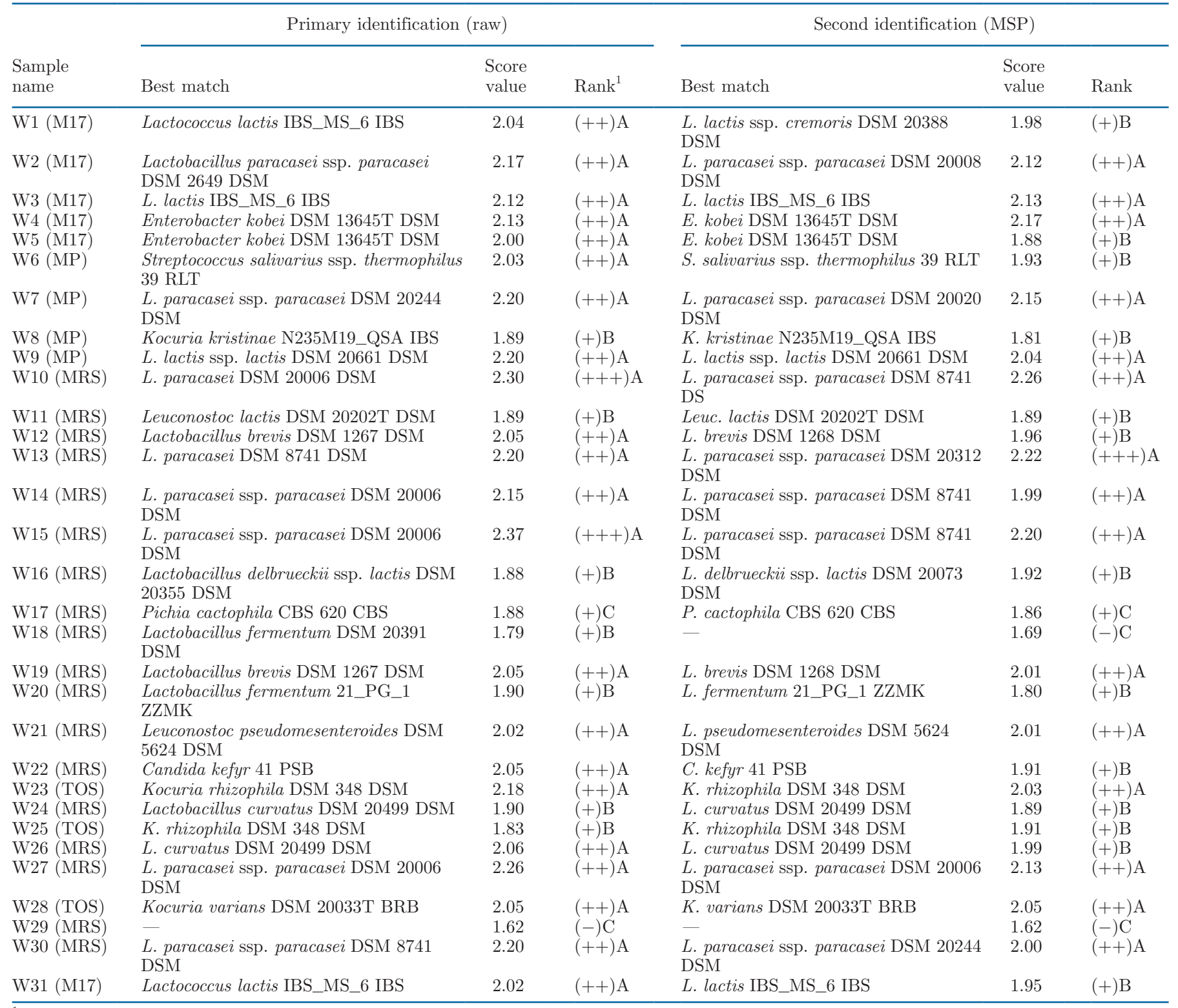

${ }^{1}$ The level of identification: $+++=$ highly probable species identification $(2.300-3.000) ;++=$ secure genus identification, probable species identification $(2.000-2.299) ;+=$ probable genus identification $(1.700-1.999) ;-=$ not reliable identification $(0.000-1.699)$. Consistency status: A $=$ high (species); $\mathrm{B}=$ low (genus); $\mathrm{C}=$ none. 
acid composition confirmed the presence of significant amounts of acids with a chain length of C16:0-C20: 0 . Among the dominant acids in the LAB fatty acid profile were palmitic acid (C16:0) and oleic acid (C18:1; Guerzoni et al., 2001; Vieira et al., 2015; Kiss et al., 2019). Acids with a lower number of carbon atoms were not found in LAB. Low content or lack of short-chain fatty acids may be associated with the lipolytic activity of Lactobacillus and Streptococcus bacteria. Lactic fermentation bacteria (especially Lactococcus and Lactobacillus) are considered to be weakly lipolytic compared with species of Pseudomonas, Acinetobacter, and Penicillium genera. Their significant lipolytic activity is most often observed during ripening of rennet cheese. These bacteria are probably responsible for the release of short-chain free fatty acids (FFA), which affect the sensory characteristics of the product (García-Cano et al., 2019). Lactic acid bacteria are able to degrade fats contained in dairy products, replacing them with methyl ketones, lactones, thioesters, keto-, and hydroxy acids, which give the final fragrance to dairy products. Lactic acid bacteria have esterases and lipases able to hydrolyze FFA, and tri-, di-, and monoacylglycerol esters to fatty acids (Yoon et al., 2018).

Fatty acids from LAB were isolated from MRS and M17 agar medium. The proportions of fatty acids slightly differed, depending on the medium used. The total sum of SFA, PUFA, and MUFA fatty acids produced during culture by the tested L. paracasei, $L$. lactis, and L. curvatus strains in MRS medium was higher compared with that obtained in M17 medium (Figure 3). The obtained differences in the content of acids produced in the 2 tested media may be the result of different fermentation metabolism of the tested LAB strains. By analyzing the sum of SFA, PUFA, and MUFA, the range of results can be seen depending on the strain and the agar medium used. In MRS and M17 agar medium, the lowest sum of SFA was obtained for L. curvatus, and the highest for L. paracasei. The composition of the fatty acid profile of the cytoplasmic membrane depends on many environmental factors, which include temperature, $\mathrm{pH}$, osmotic pressure, access to nutrients, type of medium, and incubation time (Johnsson et al., 1995). One of the most important steps in determining the composition of the medium is to select the most favorable carbon source for a given microorganism. During growth, carbon is used by bacteria as an energy source and in anabolic processes, leading to the production of carbohydrates, fat, nucleic acids, and proteins (Amaretti et al., 2010). The most commonly used carbon source is glucose, which is part of the MRS medium. The theoretical synthesis yield (1 $\mathrm{g}$ of produced fat per $1 \mathrm{~g}$ of carbon substrate used) is $33 \%$ for glucose and $30 \%$ for glycerol (Ratledge and Cohen, 2008; Armenta and Valentine, 2013). Nitrogen is another essential nutrient that must be found in the environment. Culture medium are most often supplemented with such synthetic sources of this element as ammonium sulfate, ammonium chloride, aspartate, glutamate. Triammonium citrate is component of MRS medium. Nitrogen is used by bacteria to synthesize amino acids, proteins, and nucleic acids (Ratledge and Cohen, 2008; Armenta and Valentine, 2013). The

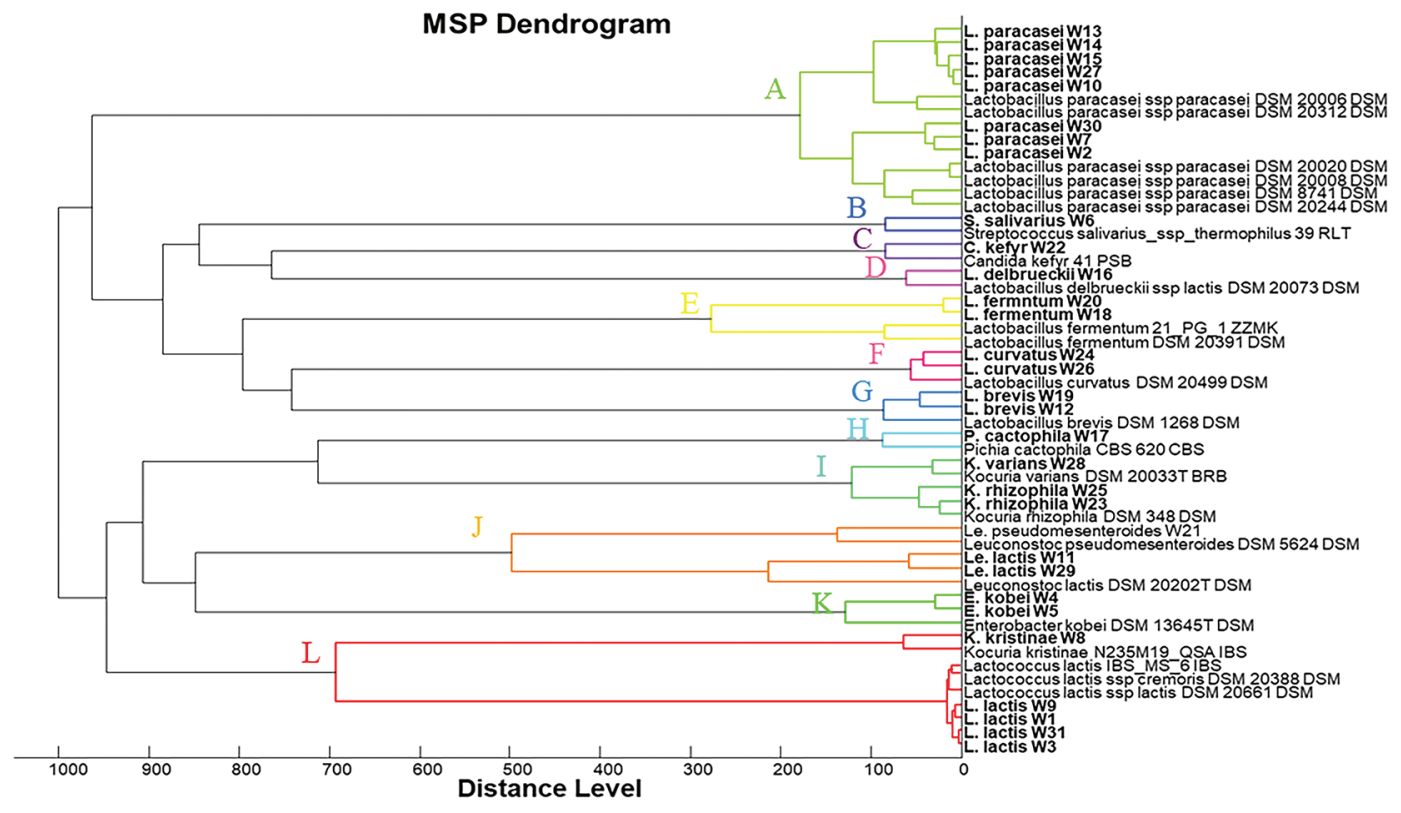

Figure 2. Phyloproteomic tree of the bacteria isolated from whey liquid. MSP = main spectra. 
process of synthesis and accumulation of fatty acids in bacterial cells is also influenced by phosphorus and microelements such as $\mathrm{Mg}^{2+}, \mathrm{Zn}^{2+}, \mathrm{Mn}^{2+}$, and $\mathrm{Ca}^{2+}$. The type of carbon and nitrogen source used in the culture medium is effect on the total content of lipids and fatty acids in bacterial cells (Kankaanpää et al., 2004). The fatty acid profile for the 3 bacterial strains also depends on the composition and concentration of nutrients in the medium used. The composition of MRS medium differs significantly from the composition of M17 medium. The MRS medium contains a higher concentration of such ingredients as enzymatic digest of casein, meat extract, yeast extract, and agar, and additionally contains glucose, dipotassium hydrogen phosphate, Tween 80, triammonium citrate, sodium acetate, magnesium sulfate heptahydrate, and manganese sulfate monohydrate that are not in M17 medium. Analyzing the content of fatty acids on MRS medium, higher content was observed for fatty acids C15:0, C16:0, C17:0, C18:0, C18:1, C18:3n-6, C18:3n -3, C20:0, C20:1, C20:2, and C20:3n-6, for all bacterial strains compared with M17 medium. It can be seen that MRS medium increases SFA. Studies have shown that the content of the Tween 80 component (in MRS medium) has a positive effect on the oleic acid content (Reitermayer et al., 2018). In addition, Tween 80 is an essential LAB growth factor (Fonseca et al., 2019).
Fatty acids embedded in PL are important for membrane structure and function. They maintain its integral structure and affect permeability. The properties of the membrane depend on straight, branched, and unsaturated acids. The increase in unsaturated acid content increases membrane fluidity and intensifies diffusion processes. In contrast, an increase in branched acids stiffens the membrane structure and reduces its permeability. Fatty acids belong to one of the most dynamic components of bacterial cells. Fatty acids are often replaced and modified in lipids. Because of this, bacteria can easily adapt to subsequent growth phases and adapt to changing environmental conditions (Šajbidor, 1997).

\section{FFA Profile by MALDI-TOF MS}

The MALDI-TOF MS technique is a useful tool in the analysis of proteins. Protein extracts from bacterial cells give characteristic spectra, which are unique to specific bacterial species and are used to identify bacteria. The MALDI-TOF MS technique is fast and reliable in the analysis of bacterial proteins. In the case of lipid analysis, MALDI-TOF MS offers several advantages, such as rapid sample preparation or the possibility of sample analysis without prior derivatization process (Angelini et al., 2010; Li et al., 2014).

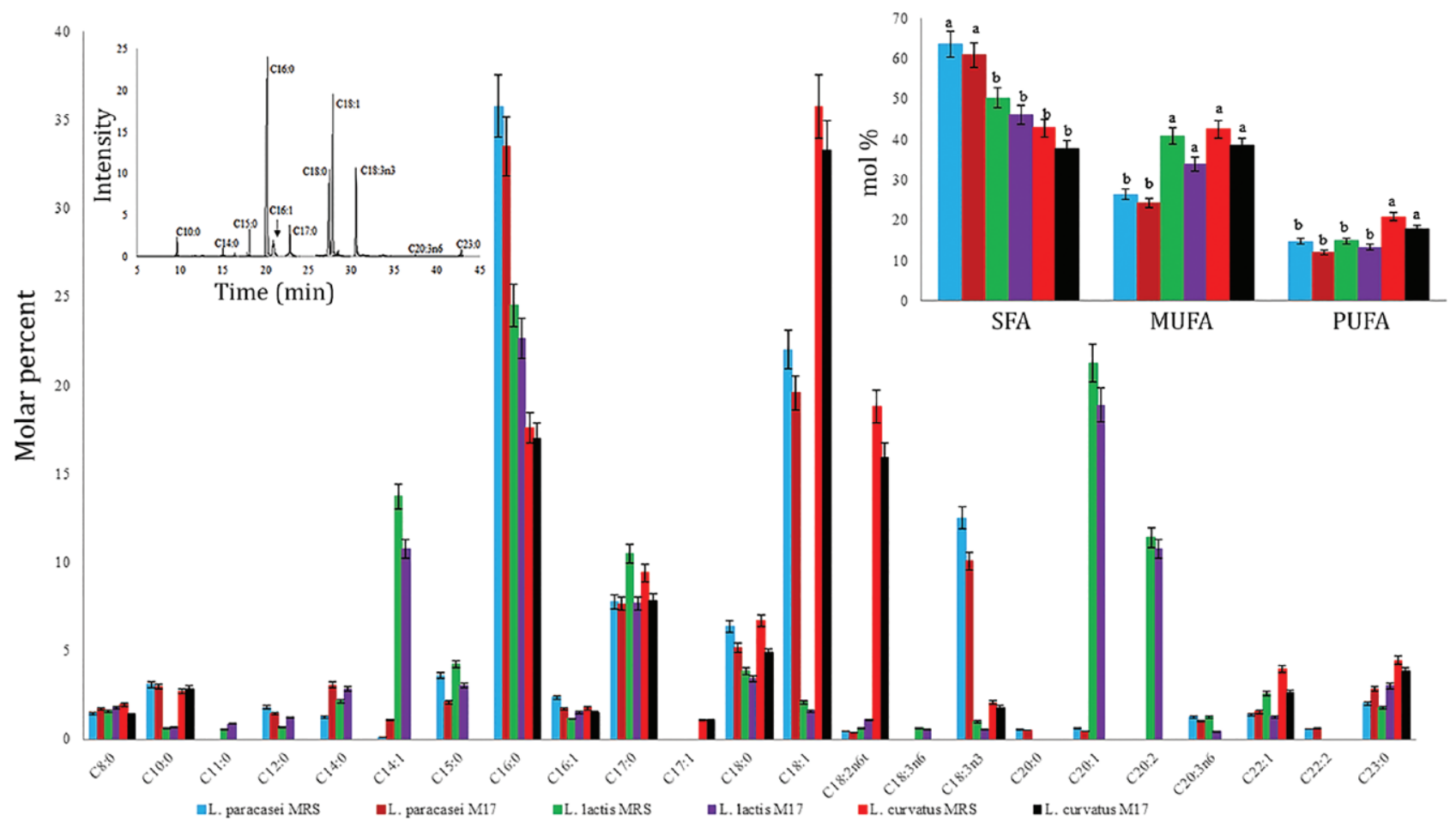

Figure 3. Composition of fatty acid profiles in 3 different bacteria. Values represent average \pm SD ( $\mathrm{n}=3$ replicates). The values within a row marked with different letters $(\mathrm{a}, \mathrm{b})$ are significantly different (at $P<0.05$ ). 
Figure $4 \mathrm{a}-\mathrm{c}$ shows the MALDI-TOF mass spectra of FFA from L. paracasei, L. lactis, and L. curvatus. In the spectrum, mainly molecular ions $[\mathrm{M}+\mathrm{H}]^{+}$can be observed. Also, in case of MUFA and PUFA, sodium adducts $[\mathrm{M}+\mathrm{Na}]^{+}$can be observed. Figure 4a shows the MALDI-TOF spectrum of FFA from L. paraca$s e i$, in which 11 fatty acids were identified, including myristic acid $(m / z 229)$, pentadecylic acid $(m / z 243)$, palmitoleic acid $(m / z 255)$, palmitic acid $(m / z 257)$, margaric acid $(m / z 271)$, oleic acid $(m / z 283)$, stearic acid $(m / z 285), \alpha$-linolenic acid $(m / z 302)$, linoleic acid $(m / z 304)$, arachidic acid $(m / z 313)$, and dihomo- $\gamma$ linolenic acid $(m / z 330)$. The MALDI-TOF spectrum of FFA from $L$. lactis revealed the presence of myristoleic acid $(m / z 227)$, myristic acid $(m / z 229)$, pentadecylic acid $(m / z 243)$, palmitoleic acid $(m / z 255)$, margaric acid $(m / z 271)$, stearic acid $(m / z 285)$, linoleic acid $(\mathrm{m} / z$ 304), paullinic acid $(\mathrm{m} / z 311)$, and eicosadienoic acid $(m / z 332$; Figure $4 \mathrm{~b})$. Only 6 FFA were identified in L. curvatus strain and they include palmitoleic acid $(\mathrm{m} / z 255)$, margaric acid $(\mathrm{m} / z 271)$, stearic acid $(\mathrm{m} / \mathrm{z}$ $285)$, linoleic acid $(m / z 304)$, oleic acid $(m / z 306)$, and 13-docosenoic acid $(\mathrm{m} / z$ 339; Figure $4 \mathrm{c})$. Comparing the GC/MS analysis of fatty acids with the MALDITOF MS analysis, we can see the agreement of the results obtained. However, much less fatty acids were identified in the MALDI-TOF MS analysis (for each bacterial strain), compared with GC/MS analysis. The use of MALDI in the analysis of FFA is challenging. The main problem is the frequent overlap of signals from the matrix and from FFA (for $m / z<500$ ). Also, too high matrix concentration causes a decrease in FFA sensitivity (Voorhees et al., 2013; Leopold et al., 2018). In the research, the DHB matrix was used, which should provide 2 signals in positive ion mode at $\mathrm{m} / z 155.1$ and 177.1 for the $\mathrm{H}^{+}$and $\mathrm{Na}^{+}$adduct, respectively. To eliminate this phenomenon, is necessary select the appropriate matrix concentration and use a matrix that does not cause interference.

\section{MALDI-TOF MS Lipid Profiles}

Lipids are one of the main components of cell membranes and play a very important role in the metabolism of living organisms. Lipidome of bacteria are very diverse and have a variable composition for various bacteria (Sohlenkamp and Geiger, 2016). A particularly important part of the lipid family is PL and derivatives of PL, which are the building blocks of bacterial membranes. Phospholipids consist of glycerol, a phosphate group, 2 fatty acids (saturated, unsaturated, or both), and a polar head. To the main components of bacterial membranes can be included phosphatidylglycerol (PG), phosphatidylethanolamine (PE), and cardiolipin
(CL), and the less frequent phosphatidylcholine (PC) and phosphatidylinositol (PI; Sohlenkamp and Geiger, 2016; López-Lara and Geiger, 2017). The MALDI-TOF MS has been used for the characterization and identification of lipids (PL and TAG) profile from LAB ( $L . p a-$ racasei, L. lactis, and L. curvatus). The MALDI spectra of lipid mixtures were recorded at mass range $\mathrm{m} / z 100$ to 1,600 in positive ion mode and used the 2 matrices HCCA and DHB. Because identification of lipids depends on the applied matrix, in the first step 2 matrices were compared, HCCA and DHB. Both matrices were dissolved in the same solvent (30:70, acetonitrile: $0.1 \%$ TFA in water). The application of HCCA and DHB gave minor differences in positive ion spectra. That means the matrix used in the research had no significant influence on lipid profiles, only the intensity was changed (Griffiths and Bunch, 2012; Leopold et al., 2018). In the second step, the LIFT MALDI-TOF/ TOF MS mode for the identification of lipid molecular species was used. The composition of fatty acids was determined from the measured exact mass product ions observed in MS/MS experiments and compared with standards. The fragmentation of selected TAG and PL is shown in Figures 5, 6, and 7.

Triacylglycerols are a broad group of compounds, which differ in the length of the acyl chains and the number of double bonds. The acyl chains can be located in the sn-1, sn-2, and sn-3 position of glycerol backbone (Yener and van Valenberg, 2019). Figure 5 presents protonated molecular ion $[\mathrm{M}+\mathrm{H}]^{+}$at $m / z$ 915.085, corresponding to TAG (20:1/20:1/16:0). The fragments at $m / z 605.796$ correspond to loss of the fatty acid 20:1 as $\left[\mathrm{M}-\mathrm{R}_{1} \mathrm{COO}\right]^{+}$and a minor ion at $\mathrm{m} / z 604.938$ correspond to the ion $\left[\mathrm{M}-\mathrm{R}_{1} \mathrm{COOH}\right]$. The fragments observable at $m / z 659.751$ and 660.245 correspond to $\left[\mathrm{M}-\mathrm{R}_{3} \mathrm{COOH}\right]$ and $\left[\mathrm{M}-\mathrm{R}_{3} \mathrm{COO}\right]^{+}$(loss of fatty acid 16:0 located at the sn-3 position), respectively. Loss of fatty acid located in sn- 2 position is energetically less favorable compared with the sn- 1 and sn-3 positions. The steric properties of the molecule contribute to this (Kurvinen et al., 2002; Yener and van Valenberg, 2019). At lower abundance the $m / z$ ions 239.314 and 293.514 correspond to palmitic $\left[\mathrm{R}_{3} \mathrm{CO}\right]^{+}$and gondoic $\left[\mathrm{R}_{1} \mathrm{CO}\right]^{+}$ ion, respectively. The ions detected at $m / z 313.491$ and 367.364 can be described as $\left[\mathrm{R}_{3} \mathrm{CO}+74\right]^{+}$and $\left[\mathrm{R}_{1} \mathrm{CO}\right.$ $+74]^{+}$ions, corresponding to palmitic and gondoic acyl moiety plus glyceryl moiety (74 mass correspond to a molecule $\mathrm{C}_{3} \mathrm{H}_{6} \mathrm{O}_{2}$ ), respectively (Haddad et al., 2012). The ion $m / z 380.517$ is probably a result of the combination of gondoic acid and glycerol backbone. The signal at $m / z 620.221$ can correspond to the ion [M $\left.\mathrm{R}_{1} \mathrm{CO}-\mathrm{H}_{2} \mathrm{O}\right]^{+}$(loss of gondoic acyl moiety) (Kurvinen et al., 2002; Haddad et al., 2012; Badu and Johannes Awudza, 2017). 
Figure 6 shows the spectra of PE (16:0/18:1), which contained sodiated adduct $\left[\mathrm{M}+\mathrm{Na}^{+}(\mathrm{m} / z\right.$ 740.767). The ions equivalent to $m / z 459.304$ and 485.205 correspond to $\left[\mathrm{M}+\mathrm{Na}-\mathrm{R}_{2} \mathrm{COOH}\right]^{+}$(loss of palmitic acid) and $\left[\mathrm{M}+\mathrm{Na}-\mathrm{R}_{1} \mathrm{COOH}\right]^{+}$(loss of oleic acid), respectively. The signals at $m / z 239.294$ and 265.261 belong to moiety of palmitic and oleic acid, respectively. The fragments at $m / z 695.544[\mathrm{M}+\mathrm{Na}-45]^{+}, 600.102$ $[\mathrm{M}+\mathrm{Na}-140]^{+}$, and $577.348[\mathrm{M}-\mathrm{Na}-163]^{+}$corresponded to the loss of ethanolamine, ethanolamine phosphate, and sodiated ethanolamine phosphate, respectively (Al-Saad et al., 2003a). The fragments equal to $m / z 164.044$ and 121.009 correspond to the neutral loss of sodiated ethanolamine phosphate $\left[\mathrm{C}_{2} \mathrm{H}_{8} \mathrm{NPO}_{4}+\right.$ $\mathrm{Na}]^{+}$and loss of ethanolamine from sodiated ethanolamine phosphate $\left[\mathrm{H}_{2} \mathrm{PO}_{4}+\mathrm{Na}\right]^{+}$, respectively. Ion at $m / z 415.275$ can be correspond to loss of oleic acid combined with ethanolamine $\left[\mathrm{M}+\mathrm{Na}-\mathrm{R}_{2} \mathrm{COOH}\right.$
- 43$]^{+}$from $\left[\mathrm{C}_{39} \mathrm{H}_{76} \mathrm{NPO}_{8} \mathrm{Na}\right]^{+}$a molecule (Pham and Julian, 2014). In case of PE molecules, the ions $\mathrm{m} / \mathrm{z}$ 43 (ethanolamine) and 141 (ethanolamine phosphate) are characteristic for this class of PL in positive mode (Al-Saad et al., 2003a; Richter et al., 2008; Pham and Julian, 2014).

Figure 7 shows the fragmentation spectra of lysophosphatidylcholine (18:0). In Figure 7 we can observe molecular ion $[\mathrm{M}+\mathrm{H}]^{+}$at $m / z$ 524.234. The most intense signal at $m / z 184.198$ corresponds to choline phosphate $\left[\mathrm{C}_{5} \mathrm{H}_{15} \mathrm{NPO}_{4}\right]^{+}$, which is by "fingerprint" of the molecule PC class (Al-Saad et al., 2003b; Schiller et al., 2004). The less intense ions at $m / z$ 104.019, 86.004 , and 59.962 result from neutral loss of choline $\left[\mathrm{C}_{5} \mathrm{H}_{14} \mathrm{NO}\right]^{+}$, "dehydrocholine" $\left[\mathrm{C}_{5} \mathrm{H}_{12} \mathrm{~N}\right]^{+}$, and trimethylamine $\left[\mathrm{C}_{3} \mathrm{H}_{9} \mathrm{~N}\right]$, respectively. The ion equal at $\mathrm{m} / z$ 257.126 probably corresponds to the loss of stearic acyl moiety $[\mathrm{M}-\mathrm{RCO}]^{+}$. The signal detected at $m / z 267.225$

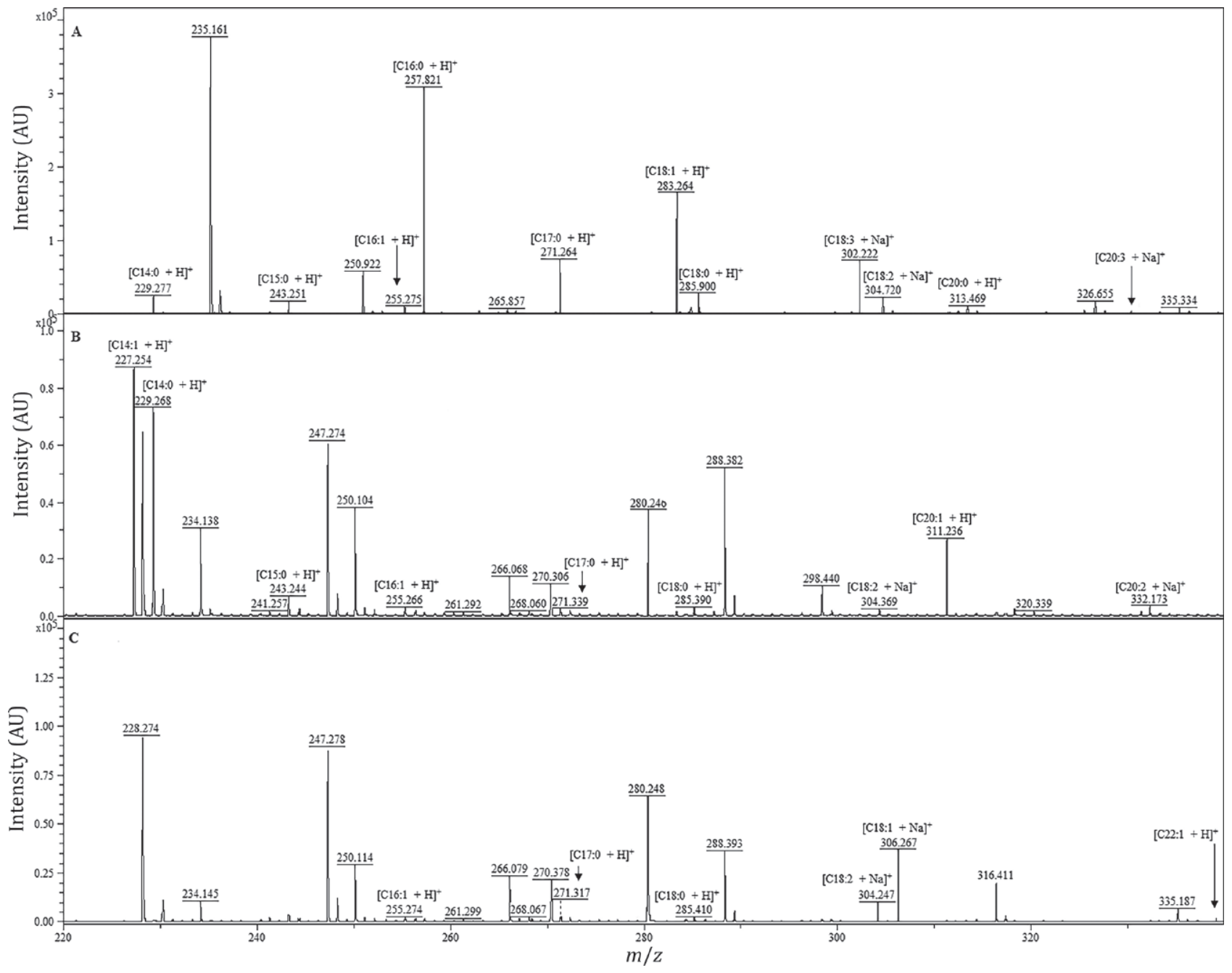

Figure 4. MALDI-TOF MS spectrum of free fatty acids for selected bacteria (1) Lactobacillus paracasei, (2) Lactococcus lactis, and (3) Lactobacillus curvatus.. $m / z=$ mass-to-charge ratio; $\mathrm{AU}=$ arbitrary units. 
corresponds to the moiety of stearic acyl. The small intense signals at $m / z 341.276$ and 420.010 correspond to loss of choline phosphate $\left[\mathrm{M}+\mathrm{H}-\mathrm{C}_{5} \mathrm{H}_{15} \mathrm{NPO}_{4}\right]^{+}$ and choline $\left[\mathrm{M}+\mathrm{H}-\mathrm{C}_{5} \mathrm{H}_{14} \mathrm{NO}\right]^{+}$, respectively.

Table 3 shows all the identified molecular ions obtained for the lipids from LAB. Pluses mean that the molecular species of lipid is present in L. paracasei, $L$. lactis or L. curvatus. Seventy-nine molecular species of total lipids [52 PL, 1 sphingomyelin (SM), 6 ceramides (Cer), $20 \mathrm{TAG}$ ] were identified in L. paracasei strain. 63 molecular species of total lipids (38 PL, 2 SM, 6 Cer, 17 TAG) were identified in L. lactis strain. In the case of L. curvatus strain, 38 molecular species of PL, 13 of TAG, 5 of Cer, and 2 of SM were found. The most abundant species among total PL were PG (18 molecular species), PE (16 molecular species), and TAG (23 molecular species). The 14, 9, and 9 combination of fatty acids in PG class was identified for L. paracasei, L. lactis, and L. curvatus, respectively. In case of
PE, 13, 13, and 10 molecular species were found for L. paracasei, L. lactis, and L. curvatus, respectively. Lyso-phosphatidylinositol (18:1) and phosphatidic acid (14:0/14:0) were identified only in L. paracasei strain (Table 3). Lyso-phosphatidylglycerol (18:1) was found in L. paracasei and L. curvatus strains. Lysophosphatidic acid (18:1) was observed for L. lactis and L. curvatus strains. Eight species of PC constitute all identified PL in LAB strains. Six molecular species belong to $L$. paracasei and 4 molecular species belong to L. lactis and L. curvatus. Table 2 shows 6,6 , and 5 Cer species, which were found in L. paracasei, L. lactis, and L. curvatus, respectively. Triacylglycerols are the second largest group of compounds identified (Table 3 ). Twenty molecular species was identified for $L$. paracasei strain, but in case of $L$. curvatus strain only 13 species was found.

Analysis of fatty acid content of PL and TAG isolated from $3 \mathrm{LAB}$ strains present the different composition of

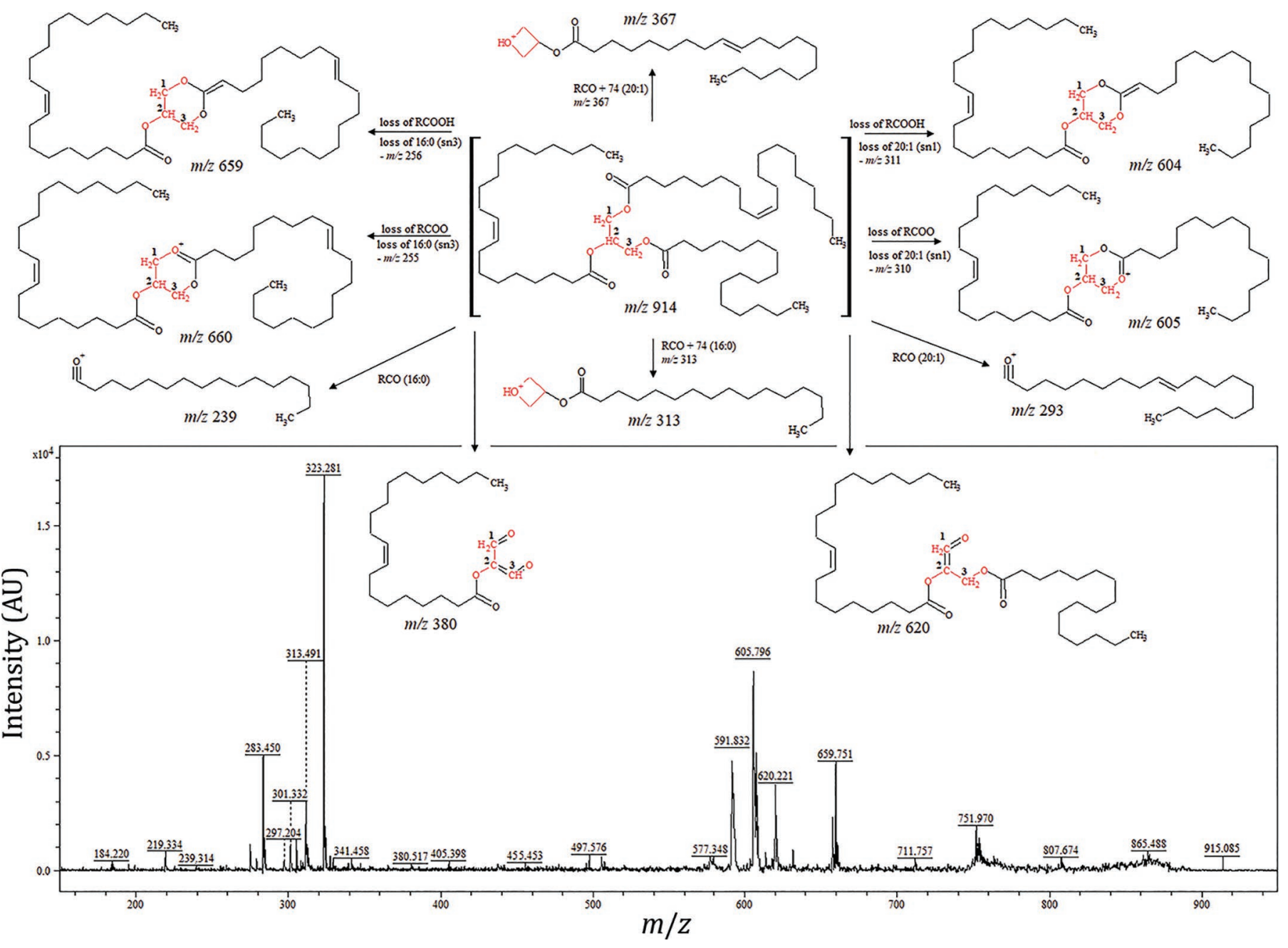

Figure 5. MALDI-TOF MS spectra and fragmentation pathway of triacylglycerols $(20: 1 / 20: 1 / 16: 0) \mathrm{m} / z$ 915.085.. $\mathrm{m} / z=$ mass-to-charge ratio; $\mathrm{AU}=$ arbitrary units. 
lipid profiles (Table 3 ). The most abundant fatty acids for all LAB strains, which build the lipid molecules, are C16:0 (palmitic acid), C16:1 (palmitoleic acid), C18:0 (stearic acid), and C18:3 ( $\alpha$-linoleic acid). The $\mathrm{n}-3$ and n-6 fatty acids, such as 18:2n-6 (linoleic acid), 18:3n-3 ( $\alpha$-linoleic acid), and 20:4n-6 (arachidonic acid), have also been identified in the strains of LAB tested (Table $3)$. The obtained results shows that bacteria membrane lipids are different for tested bacteria species. Different types of bacteria have different structural compositions of cell membranes. This is probably due to the environmental conditions that the bacteria are exposed to (Sohlenkamp and Geiger, 2016; López-Lara and Geiger, 2017). The lipid composition of bacterial cell membranes is diverse, and this is due to the diversity of amphiphilic lipids, such as PG, PE, CL, PC, phosphatidylinositol, and several other lipids. Studies on the lipid composition show that the obtained lipid profile for L. paracasei, L. lactis, and L. curvatus is charac- teristic and unique. Lipid composition of LAB strains consists of 6 main lipids: PG, PE, PI, PC, TAG, and Cer. Phosphatidylglycerol is the main phospholipid for lactic bacteria and is responsible for temperature stress. Phosphatidylethanolamine is responsible for membrane architecture and bacterial mobility and is a precursor in the synthesis of LPS. Phosphatidylinositol plays a key role in cellular processes such as bacterial membrane dynamics (Sohlenkamp and Geiger, 2016; López-Lara and Geiger, 2017). Phosphatidylcholine is responsible for symbiotic interactions and resistance to heavy metals (Kondakova et al., 2015a). Triacylglycerols are the reserve and energetic material of bacterial cells. In addition, TAG regulate the level of membrane lipids to adapt the bacteria to the environment, and play the function in storage of lipids. The TAG are also precursors in the synthesis of PL (Alvarez and Steinbüchel, 2002; Gao and Li, 2018; Doi, 2019). Ceramides act as a protective and water-holding barrier in cells (Lew and
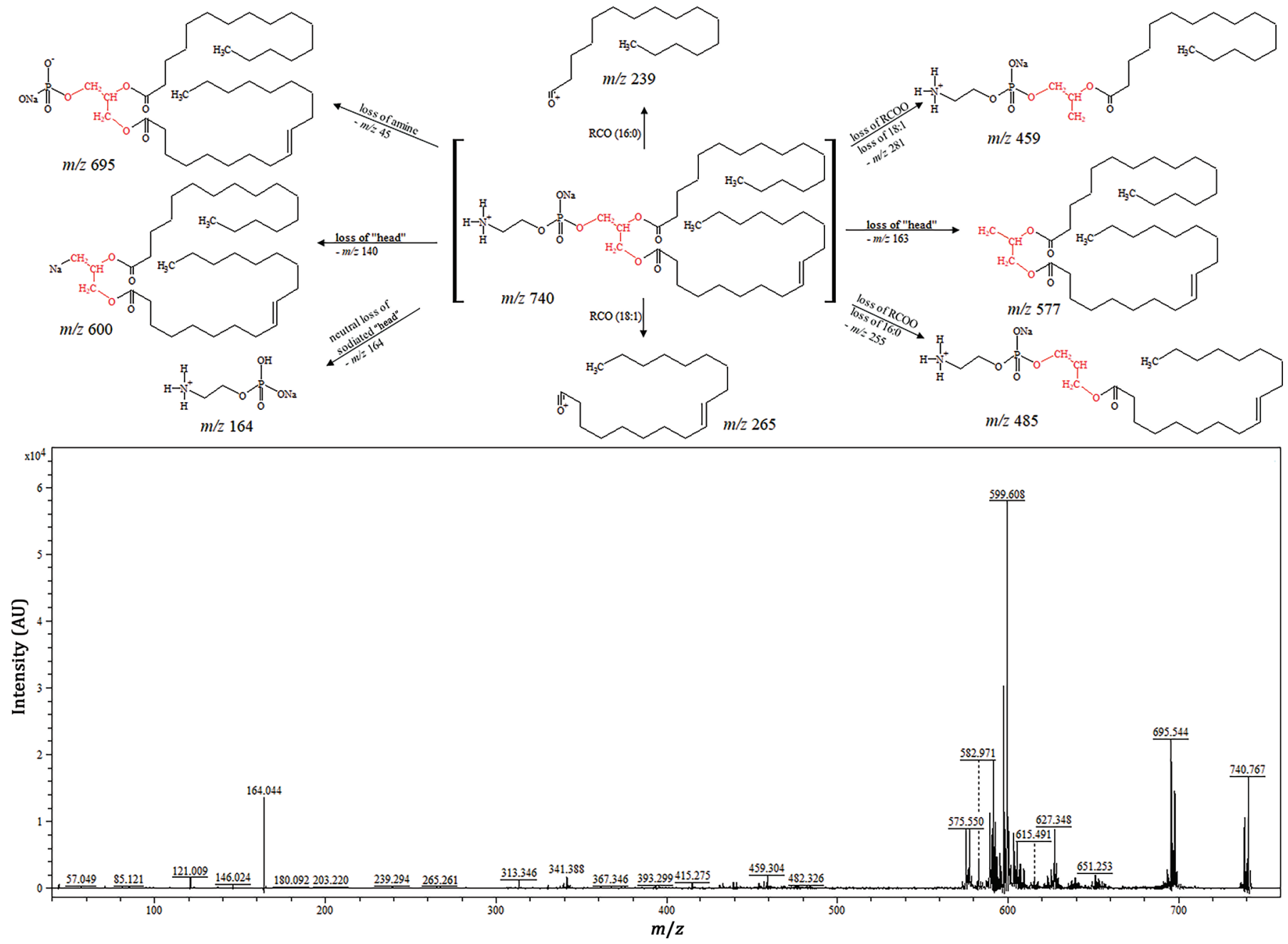

Figure 6. MALDI-TOF MS spectra and fragmentation pathway of phosphatidylethanolamine $(16: 0 / 18: 1+\mathrm{Na}) \mathrm{m} / z 740.767 . . \mathrm{m} / z=$ massto-charge ratio; $\mathrm{AU}=$ arbitrary units. 
Liong, 2013). Phosphatidylserine is a precursor in the synthesis of PE (Kondakova et al., 2015a). Phosphatidic acid is involved in cell growth, proliferation, and reproduction (Wang et al., 2006). Sphingomyelin, which is a representative of sphingolipids ( $\mathbf{S P}$ ), is a component of the cytoplasmic membrane and is involved in a variety of cellular processes such as proliferation, apoptosis, and migration (Phillips-Farfán et al., 2016; Hosomi et al., 2020). In addition, it participates in the formation of lipid rafts (Sohlenkamp and Geiger, 2016). As in the research of Drucker et al. (1995), in the case of gram-positive bacteria, the vast majority of polar lipids consisted of PG, PE, and PC. Many reports in the literature have characterized the lipid profile of bacteria, and each of these profiles is characteristic of a particular bacterial strain (Barák and Muchová, 2013; Kondakova et al., 2015b; Garrett, 2017).

\section{CONCLUSIONS}

The identification and characterization of lipid profiles for 3 species of LAB (L. paracasei, L. lactis, and $L$. curvatus) by GC/MS and MALDI-TOF MS were determined. The MALDI-TOF MS technique is very useful for the identification of microorganisms, and it is used for characterization of the bacterial lipid profile, the so-called fingerprint. This research used the MALDI BioTyper platform to identify lipids in LAB. The use of MALDI BioTyper has enabled faster and accurate identification of microorganisms, and has excluded the use of microbiological analysis and sequencing to identify microorganisms. In addition, in the future MALDITOF MS can be successfully used as a fast screening technique for analyzing, identifying, and characterizing lipids in studied bacterial strains. The 100 combinations of fatty acids were identified in tested LAB strains. Seventy-nine molecular species of total lipids (52 PL, 1 $\mathrm{SM}, 6$ Cer, and $20 \mathrm{TAG}$ ) were identified in L. paracasei strain, 63 of total lipids (38 PL, 2 SM, 6 Cer, and 17 TAG) were identified in L. lactis strain, and 58 of total lipids (38 PL, 13 TAG, 5 Cer, and $2 \mathrm{SM}$ ) were identified in L. curvatus strain. The C16:0, C16:1, C18:0, C18:3 acyl chains were contained in the major components of bacterial lipids, such as PG, PE, TAG, PI, PC, and Cer
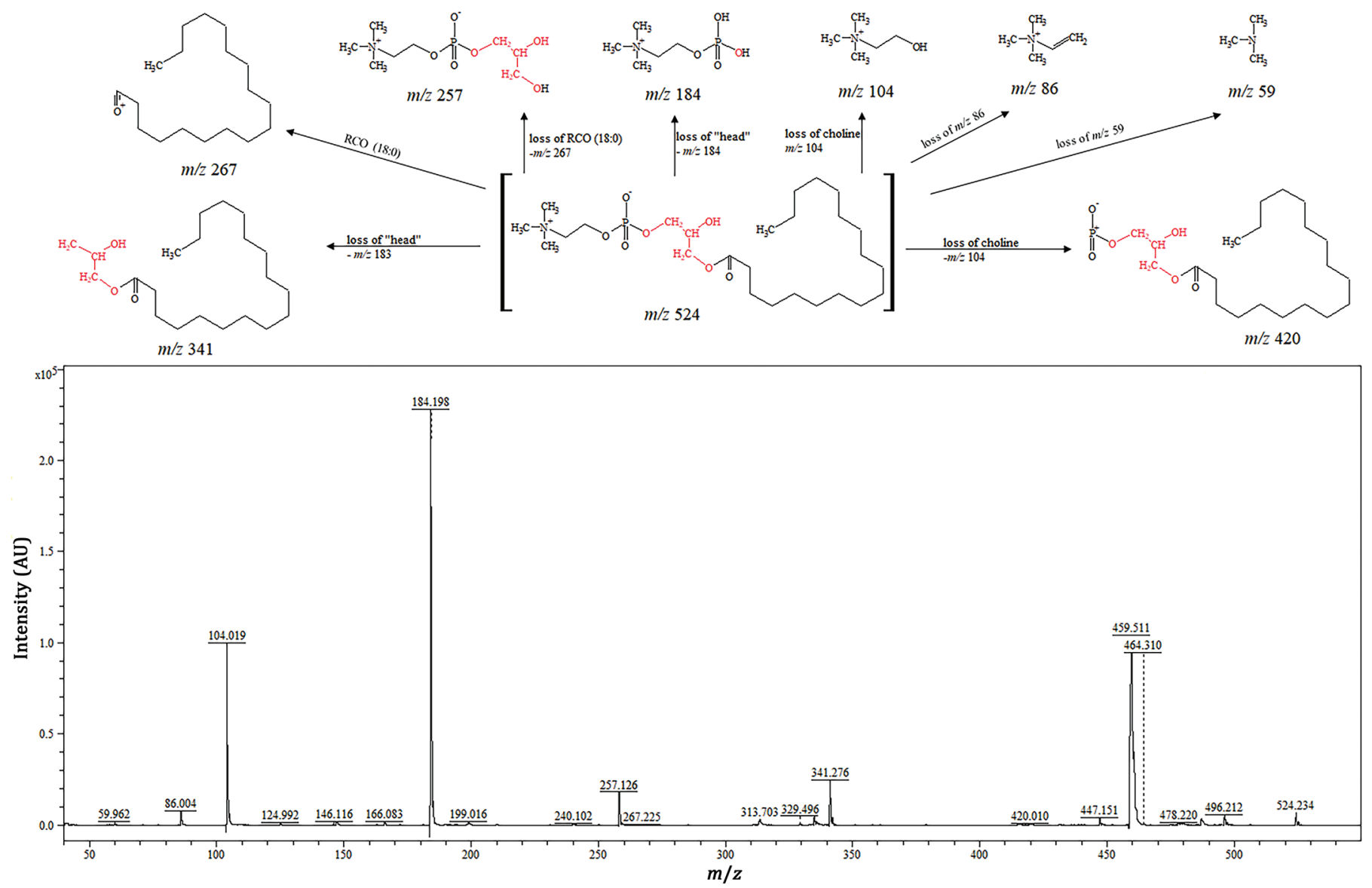

Figure 7. MALDI-TOF MS spectra and fragmentation pathway of lyso-phosphatidylcholine (18:0) $m / z$ 524.234.. $\mathrm{m} / z=$ mass-to-charge ratio; $\mathrm{AU}=$ arbitrary units. 
Table 3. Summary of lipid molecular species identified in Lactobacillus paracasei, Lactococcus lactis, and Lactobacillus curvatus by MALDITOF/TOF MS

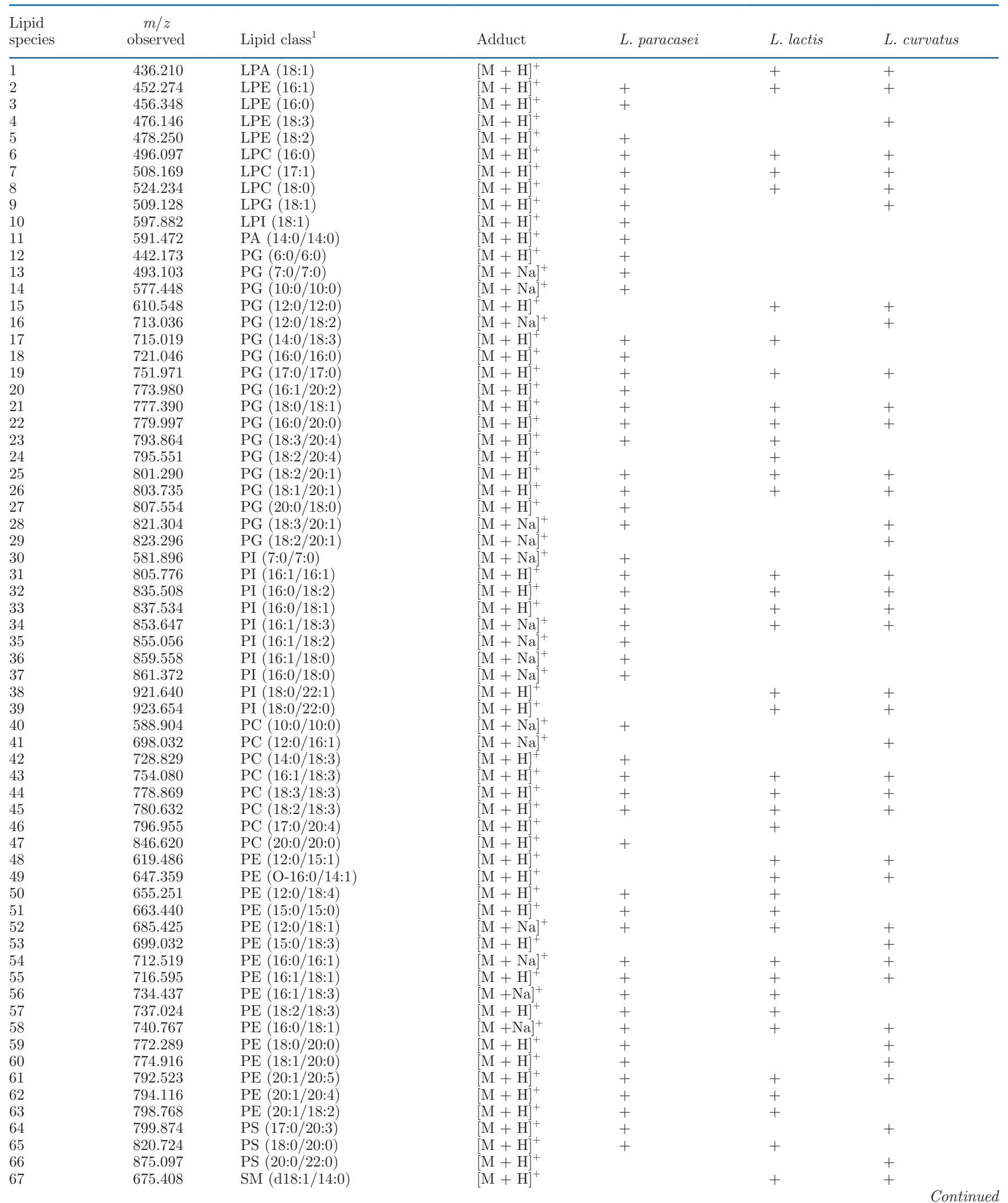


Table 3 (Continued). Summary of lipid molecular species identified in Lactobacillus paracasei, Lactococcus lactis, and Lactobacillus curvatus by MALDI-TOF/TOF MS

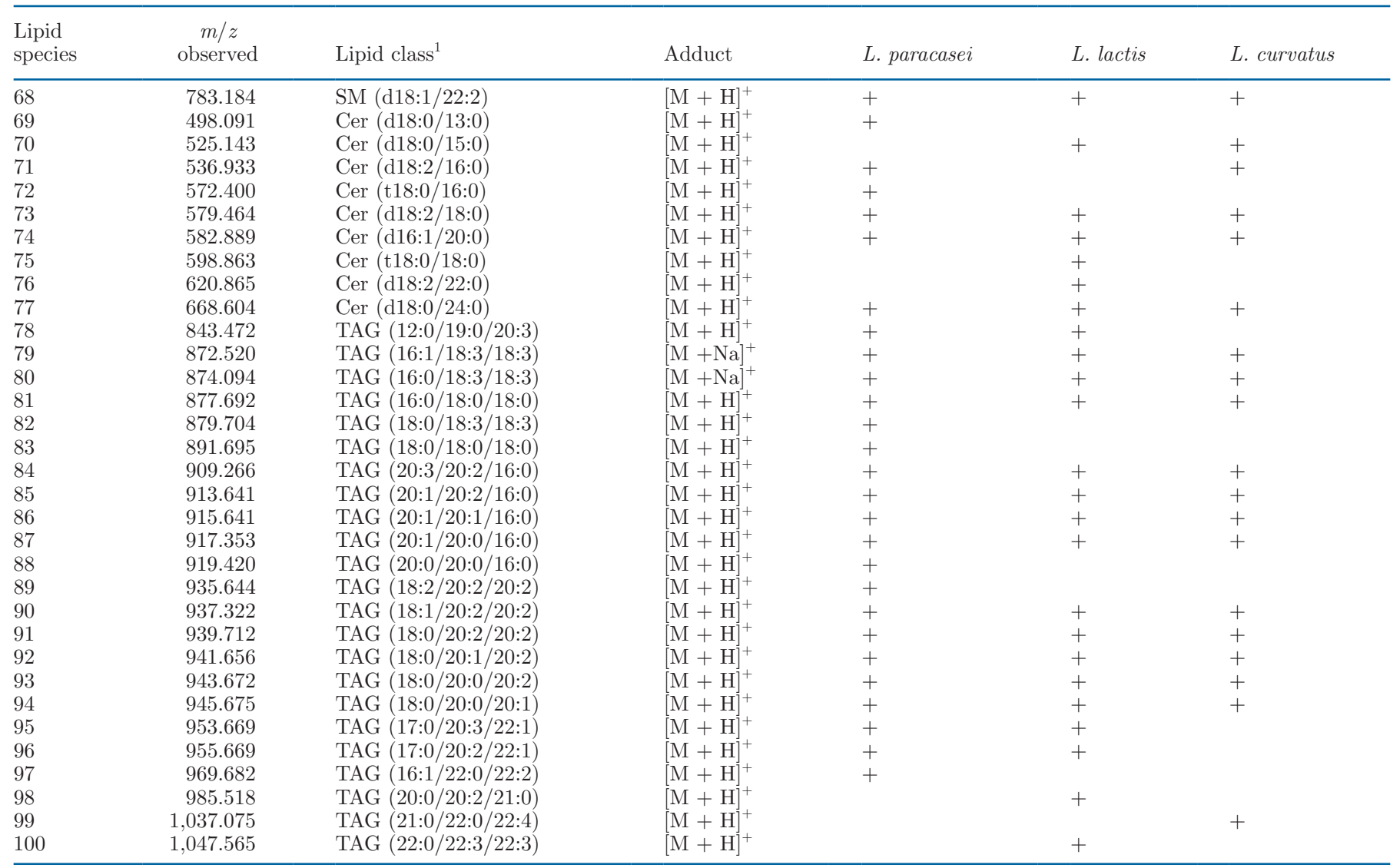

${ }^{1} \mathrm{LPA}=$ lyso-phosphatidic acid; LPE = lyso-phosphatidylethanolamine; LPC = lyso-phosphatidylcholine; LPG = lyso-phosphatidylglycerol; LPI = lyso-phosphatidylinositol; $\mathrm{PA}=$ phosphatidic acid; $\mathrm{PG}=$ phosphatidylglycerol; $\mathrm{PI}=$ phosphatidylinositol; $\mathrm{PC}=$ phosphatidylcholine; $\mathrm{PE}=$ phosphatidylethanolamine; $\mathrm{PS}=$ phosphatidylserine; $\mathrm{SM}=$ sphingomyelin; $\mathrm{Cer}=$ ceramide; $\mathrm{TAG}=$ triacylglycerol.

species. The DHB and HCCA matrices exhibit a lower signal to noise ratio and do not significantly influence lipid spectra. Twenty-three fatty acids were identified by GC/MS analysis. The use of MRS agar medium increases the content of SFA, MUFA, and PUFA. The huge variety of lipids in bacterial cells is due to various environmental conditions in which bacteria live, which cause changes in the composition of lipids in the membranes, such as temperature change, low or high $\mathrm{pH}$, and osmolarity. In addition, in the event of environmental changes, bacteria also change the composition of membrane lipids. This means that each bacteria strain has its own characteristic, unique lipid profile.

\section{ACKNOWLEDGMENTS}

This work was supported by the Opus 14 No. 2017/27/B/ST4/02628 (2018-2021) from the National Science Centre, Poland. B.B., P.P., and M.Z. are a members of the Torun Center of Excellence "Towards
Personalized Medicine" operating under Excellence Initiative-Research University (Torun, Poland). The authors have not stated any conflicts of interest.

\section{REFERENCES}

Al-Saad, K. A., W. F. Siems, H. H. Hill, V. Zabrouskov, and N. R. Knowles. 2003b. Structural analysis of phosphatidylcholines by post-source decay matrix-assisted laser desorption/ionization time-of-flight mass spectrometry. J. Am. Soc. Mass Spectrom. 14:373-382. https://doi.org/10.1016/S1044-0305(03)00068-0.

Al-Saad, K. A., V. Zabrouskov, W. F. Siems, N. R. Knowles, R. M. Hannan, and H. H. Hill. 2003a. Matrix-assisted laser desorption/ ionization time-of-flight mass spectrometry of lipids: Ionization and prompt fragmentation patterns. Rapid Commun. Mass Spectrom. 17:87-96. https://doi.org/10.1002/rcm.858.

Albano, C., S. Morandi, T. Silvetti, M. C. Casiraghi, F. Manini, and M. Brasca. 2018. Lactic acid bacteria with cholesterol-lowering properties for dairy applications: In vitro and in situ activity. J. Dairy Sci. 101:10807-10818. https://doi.org/10.3168/jds.2018 -15096 .

Alvarez, H. M., and A. Steinbüchel. 2002. Triacylglycerols in prokaryotic microorganisms. Appl. Microbiol. Biotechnol. 60:367-376. https://doi.org/10.1007/s00253-002-1135-0.

Amaretti, A., S. Raimondi, M. Sala, L. Roncaglia, M. De Lucia, A. Leonardi, and M. Rossi. 2010. Single cell oils of the cold-adapted 
oleaginous yeast Rhodotorula glacialis DBVPG 4785. Microb. Cell Fact. 9:73. https://doi.org/10.1186/1475-2859-9-73.

Angelini, R., F. Babudri, S. Lobasso, and A. Corcelli. 2010. MALDITOF/MS analysis of archaebacterial lipids in lyophilized membranes dry-mixed with 9-aminoacridine. J. Lipid Res. 51:2818 2825. https://doi.org/10.1194/jlr.D007328.

Armenta, R. E., and M. C. Valentine. 2013. Single-cell oils as a source of omega-3 fatty acids: An overview of recent advances. J. Am. Oil Chem. Soc. 90:167-182. https://doi.org/10.1007/s11746-012 $-2154-3$

Badu, M., and A. M. Johannes Awudza. 2017. Determination of the triacylglycerol content for the identification and assessment of purity of shea butter fat, peanut oil, and palm kernel oil using MALDI-TOF/TOF mass spectroscopic technique. Int. J. Food Prop. 20:271-280. https://doi.org/10.1080/10942912.2016.1155056.

Barák, I., and K. Muchová. 2013. The role of lipid domains in bacterial cell processes. Int. J. Mol. Sci. 14:4050-4065. https://doi.org/ 10.3390/ijms14024050.

Bottazzi, V. 1983. Food and feed production with microorganisms. Biotechnology 5:315-363.

Bridge, A., J. Brown, H. Snider, M. Nasato, W. E. Ward, B. D. Roy, and A. R. Josse. 2019. Greek yogurt and 12 weeks of exercise training on strength, muscle thickness and body composition in lean, untrained, university-aged males. Front. Nutr. 6:55. https://doi .org/10.3389/fnut.2019.00055.

Buszewski, B., A. Rogowska, P. Pomastowski, M. Złoch, and V. Railean-Plugaru. 2017. Identification of microorganisms by modern analytical techniques. J. AOAC Int. 100:1607-1623. https:// doi.org/10.5740/jaoacint.17-0207.

Cano-Garrido, O., J. Seras-Franzoso, and E. Garcia-Fruitós. 2015. Lactic acid bacteria: Reviewing the potential of a promising delivery live vector for biomedical purposes. Microb. Cell Fact. 14:137. https://doi.org/10.1186/s12934-015-0313-6.

Castillo Martinez, F. A., E. M. Balciunas, J. M. Salgado, J. M. Domínguez González, A. Converti, and R. P. S. Oliveira. 2013. Lactic acid properties, applications and production: A review. Trends Food Sci. Technol. 30:70-83. https://doi.org/10.1016/j.tifs.2012 .11.007.

Chocholoušková, M., R. Jirásko, D. Vrána, J. Gatěk, B. Melichar, and M. Holčapek. 2019. Reversed phase UHPLC/ESI-MS determination of oxylipins in human plasma: A case study of female breast cancer. Anal. Bioanal. Chem. 411:1239-1251. https://doi.org/10 $.1007 / \mathrm{s} 00216-018-1556-\mathrm{y}$.

Christie, W. W. 1984. Pages 33-46 in Handbook of Chromatography, vol. 1. H. K. Mangold, ed. CRC Press, Boca Raton, FL.

Daliri, E. B. M., B. H. Lee, B. J. Park, S. H. Kim, and D. H. Oh. 2018. Antihypertensive peptides from whey proteins fermented by lactic acid bacteria. Food Sci. Biotechnol. 27:1781-1789. https:// doi.org/10.1007/s10068-018-0423-0.

Doi, Y. 2019. Glycerol metabolism and its regulation in lactic acid bacteria. Appl. Microbiol. Biotechnol. 103:5079-5093. https://doi .org/10.1007/s00253-019-09830-y.

Drucker, D. B., G. Megson, D. W. Harty, I. Riba, and S. J. Gaskell. 1995. Phospholipids of Lactobacillus spp. J. Bacteriol. 177:63046308. https://doi.org/10.1128/JB.177.21.6304-6308.1995.

Dušková, M., O. Šedo, K. Kšicová, Z. Zdráhal, and R. Karpíšková. 2012. Identification of lactobacilli isolated from food by genotypic methods and MALDI-TOF MS. Int. J. Food Microbiol. 159:107114. https://doi.org/10.1016/j.ijfoodmicro.2012.07.029.

Fahy, E., S. Subramaniam, H. A. Brown, C. K. Glass, A. H. Merrill Jr., R. C. Murphy, C. R. H. Raetz, D. W. Russell, Y. Seyama, W. Shaw, T. Shimizu, F. Spener, G. van Meer, M. S. Van Nieuwenhze, S. H. White, J. L. Witztum, and E. A. Dennis. 2005. A comprehensive classification system for lipids. J. Lipid Res. 46:839-862. https://doi.org/10.1194/jlr.E400004-JLR200.

Fahy, E., M. Sud, D. Cotter, and S. Subramaniam. 2007. LIPID MAPS online tools for lipid research. Nucleic Acids Res. 35(Web Server):W606-W616. https://doi.org/10.1093/nar/gkm324.

Fijan, S. 2014. Microorganisms with claimed probiotic properties: An overview of recent literature. Int. J. Environ. Res. Public Health 11:4745-4767. https://doi.org/10.3390/ijerph110504745.
Folch, J., M. Lees, and G. H. Sloane Stanley. 1957. A simple method for the isolation and purification of total lipids from animal tissues. J. Biol. Chem. 226:497-509.

Fonseca, F., C. Pénicaud, E. E. Tymczyszyn, A. Gómez-Zavaglia, and S. Passot. 2019. Factors influencing the membrane fluidity and the impact on production of lactic acid bacteria starters. Appl. Microbiol. Biotechnol. 103:6867-6883. https://doi.org/10.1007/ s00253-019-10002-1.

Gao, Y., and D. Li. 2018. Screening of lactic acid bacteria with cholesterol-lowering and triglyceride-lowering activity in vitro and evaluation of probiotic function. Ann. Microbiol. 68:537-545. https:// doi.org/10.1007/s13213-018-1360-0.

García-Cano, I., D. Rocha-Mendoza, J. Ortega-Anaya, K. Wang, E. Kosmerl, and R. Jiménez-Flores. 2019. Lactic acid bacteria isolated from dairy products as potential producers of lipolytic, proteolytic and antibacterial proteins. Appl. Microbiol. Biotechnol. 103:5243-5257. https://doi.org/10.1007/s00253-019-09844-6.

Garrett, T. A. 2017. Major roles for minor bacterial lipids identified by mass spectrometry. Biochim. Biophys. Acta Mol. Cell Biol. Lipids 1862:1319-1324. https://doi.org/10.1016/j.bbalip.2016.10.003.

Griffiths, R. L., and J. Bunch. 2012. A survey of useful salt additives in matrix assisted laser desorption/ionization mass spectrometry and tandem mass spectrometry of lipids: Introducing nitrates for improved analysis. Rapid Commun. Mass Spectrom. 26:1557-1566. https://doi.org/10.1002/rcm.6258.

Guerzoni, M. E., R. Lanciotti, and P. S. Cocconcelli. 2001. Alteration in cellular fatty acid composition as a response to salt, acid, oxidative and thermal stresses in Lactobacillus helveticus. Microbiology 147:2255-2264. https://doi.org/10.1099/00221287-147-8-2255.

Haddad, I., M. Mozzon, R. Strabbioli, and N. G. Frega. 2012. A comparative study of the composition of triacylglycerol molecular species in equine and human milks. Dairy Sci. Technol. 92:37-56. https://doi.org/10.1007/s13594-011-0042-5.

Hall, T. A. 1999. BioEdit: A user-friendly biological sequence alignment editor and analysis program for Windows 95/98/NT. Nucl. Acids. Symp. Ser. 41 95-98. https://doi.org/10.14601/Phytopathol _Mediterr-14998u1.29.

Hosomi, K., H. Kiyono, and J. Kunisawa. 2020. Fatty acid metabolism in the host and commensal bacteria for the control of intestinal immune responses and diseases. Gut Microbes 11:276-284. https:/ /doi.org/10.1080/19490976.2019.1612662.

Jeong, J. H., C. Y. Lee, and D. K. Chung. 2016. Probiotic lactic acid bacteria and skin health. Crit. Rev. Food Sci. Nutr. 56:2331-2337. https://doi.org/10.1080/10408398.2013.834874.

Johnsson, T., P. Nikkila, L. Toivonen, H. Rosenqvist, and S. Laakso. 1995. Cellular fatty acid profiles of lactobacillus and lactococcus strains in relation to the oleic acid content of the cultivation medium. Appl. Environ. Microbiol. 61:4497-4499. https://doi.org/10 .1128/AEM.61.12.4497-4499.1995.

Jørgensen, C. E., R. K. Abrahamsen, E.-O. Rukke, T. K. Hoffmann, A.-G. Johansen, and S. B. Skeie. 2019. Processing of high-protein yoghurt. A review. Int. Dairy J. 88:42-59. https://doi.org/10 $.1016 /$ j.idairyj.2018.08.002.

Kankaanpää, P., B. Yang, H. Kallio, E. Isolauri, and S. Salminen. 2004. Effects of polyunsaturated fatty acids in growth medium on lipid composition and on physicochemical surface properties of Lactobacilli. Appl. Environ. Microbiol. 70:129-136. https://doi .org/10.1128/AEM.70.1.129-136.2004.

Kiss, A., Z. Naár, L. Daróczi, S. Kukovics, F. Kukovics, I. Mirmazloum, and E. Némedi. 2019. Changes of free fatty acid composition and number of lactic acid bacteria in three functional goat and sheep milk products fortified with inulin or fish oil. J. Food 17:51-59. https://doi.org/10.1080/19476337.2018.1551936.

Komprda, T. 2012. Eicosapentaenoic and docosahexaenoic acids as inflammation-modulating and lipid homeostasis influencing nutraceuticals: A review. J. Funct. Foods 4:25-38. https://doi.org/10 $.1016 /$ j.jff.2011.10.008.

Kondakova, T., F. D'Heygère, M. J. Feuilloley, N. Orange, H. J. Heipieper, and C. Duclairoir Poc. 2015a. Glycerophospholipid synthesis and functions in Pseudomonas. Chem. Phys. Lipids 190:2742. https://doi.org/10.1016/j.chemphyslip.2015.06.006. 
Kondakova, T., N. Merlet-Machour, M. Chapelle, D. Preterre, F. Dionnet, M. Feuilloley, N. Orange, and C. Duclairoir Poc. 2015b. A new study of the bacterial lipidome: HPTLC-MALDI-TOF imaging enlightening the presence of phosphatidylcholine in airborne Pseudomonas fluorescens MFAF76a. Res. Microbiol. 166:1-8. https://doi.org/10.1016/j.resmic.2014.11.003.

Król, A., P. Pomastowski, K. Rafińska, V. Railean-Plugaru, J. Walczak, and B. Buszewski. 2018. Microbiology neutralization of zearalenone using Lactococcus lactis and Bifidobacterium sp. Anal. Bioanal. Chem. 410:943-952. https://doi.org/10.1007/s00216-017 $-0555-8$.

Kurvinen, J. P., O. Sjovall, and H. Kallio. 2002. Molecular weight distribution and regioisomeric structure of triacylglycerols in some common human milk substitutes. J. Am. Oil Chem. Soc. 79:13-22. https://doi.org/10.1007/s11746-002-0428-3.

Layman, D. K., B. Lönnerdal, and J. D. Fernstrom. 2018. Applications for a-lactalbumin in human nutrition. Nutr. Rev. 76:444-460. https://doi.org/10.1093/nutrit/nuy004.

Leopold, J., Y. Popkova, K. M. Engel, and J. Schiller. 2018. Recent developments of useful MALDI matrices for the mass spectrometric characterization of lipids. Biomolecules 8:173. https://doi.org/ 10.3390/biom8040173.

Lew, L. C., and M. T. Liong. 2013. Bioactives from probiotics for dermal health: Functions and benefits. J. Appl. Microbiol. 114:12411253. https://doi.org/10.1111/jam.12137.

Li, L., J. Han, Z. Wang, J. Liu, J. Wei, S. Xiong, and Z. Zhao. 2014. Mass spectrometry methodology in lipid analysis. Int. J. Mol. Sci. 15:10492-10507. https://doi.org/10.3390/ijms150610492.

Liu, Z., S. Rochfort, and B. Cocks. 2018. Milk lipidomics: What we know and what we don't. Prog. Lipid Res. 71:70-85. https://doi .org/10.1016/j.plipres.2018.06.002.

López-Lara, I. M., and O. Geiger. 2017. Bacterial lipid diversity. Biochim. Biophys. Acta Mol. Cell Biol. Lipids 1862:1287-1299. https: //doi.org/10.1016/j.bbalip.2016.10.007.

Matarese, L. E., D. L. Seidner, and E. Steiger. 2003. The role of probiotics in gastrointestinal disease. Nutr. Clin. Pract. 18:507-516. https://doi.org/10.1177/0115426503018006507.

Monod, J. 1949. The growth of bacterial cultures. Annu. Rev. Microbiol. 3:371-394. https://doi.org/10.1146/annurev.mi.03.100149 .002103.

Pavli, F. G., A. A. Argyri, O. S. Papadopoulou, G. J. E. Nychas, N. G. Chorianopoulos, and C. C. Tassou. 2016. Probiotic potential of lactic acid bacteria from traditional fermented dairy and meat products: assessment by in vitro tests and molecular characterization. J. Prob. Health 4:157. https://doi.org/10.4172/2329-8901 .1000157 .

Peltonen, K., H. El-Nezami, C. Haskard, J. Ahokas, and S. Salminen. 2001. Aflatoxin $B_{1}$ binding by dairy strains of lactic acid bacteria and bifidobacteria. J. Dairy Sci. 84:2152-2156. https://doi.org/10 .3168/jds.S0022-0302(01)74660-7.

Peterka, O., R. Jirásko, M. Chocholoušková, L. Kuchař, D. Wolrab, R. Hájek, D. Vrána, O. Strouhal, B. Melichar, and M. Holčapek. 2020. Lipidomic characterization of exosomes isolated from human plasma using various mass spectrometry techniques. Biochim. Biophys. Acta Mol. Cell. Biol. Lipids 1865:158634. https://doi.org/10 .1016/j.bbalip.2020.158634.

Pham, H. T., and R. R. Julian. 2014. Radical delivery and fragmentation for structural analysis of glycerophospholipids. Int. J. Mass Spectrom. 370:58-65. https://doi.org/10.1016/j.ijms.2014.06.022.

Phillips-Farfán, B., K. Carvajal, A. E. Medina-Torres, S. E. EspinosaPadilla, G. Fabrias, and L. Camacho. 2016. Sphingolipids as mediators in the crosstalk between microbiota and intestinal cells: Implications for inflammatory bowel disease. Mediators Inflamm. 2016:9890141. https://doi.org/10.1155/2016/9890141.

Piqué, N., M. Berlanga, and D. Miñana-Galbis. 2019. Health benefits of heat-killed (Tyndallized) probiotics: An overview. Int. J. Mol. Sci. 20:2534. https://doi.org/10.3390/ijms20102534.

Pomastowski, P., M. Złoch, A. Rodzik, M. Ligor, M. Kostrzewa, and B. Buszewski. 2019. Analysis of bacteria associated with honeys of different geographical and botanical origin using two different identification approaches: MALDI-TOF MS and $16 \mathrm{~S}$ rDNA PCR technique. PLoS One 14:e0217078. https://doi.org/10.1371/ journal.pone.0217078.

Pulfer, M., and R. C. Murphy. 2003. Electrospray mass spectrometry of phospholipids. Mass Spectrom. Rev. 22:332-364. https://doi .org/10.1002/mas.10061.

Ratledge, C., and Z. Cohen. 2008. Microbial and algal oils: Do they have a future for biodiesel or as commodity oils? Lipid Technol. 20:155-160. https://doi.org/10.1002/lite.200800044.

Reitermayer, D., T. A. Kafka, C. A. Lenz, and R. F. Vogel. 2018. Interrelation between Tween and the membrane properties and high pressure tolerance of Lactobacillus plantarum. BMC Microbiol. 18:72. https://doi.org/10.1186/s12866-018-1203-y.

Richter, G., C. Schober, R. Süß, B. Fuchs, C. Birkemeyer, and J. Schiller. 2008. Comparison of the positive and negative ion electrospray ionization and matrix-assisted laser desorption ionization-time-offlight mass spectra of the reaction products of phosphatidylethanolamines and hypochlorous acid. Anal. Biochem. 376:157-159. https://doi.org/10.1016/j.ab.2008.01.029.

Šajbidor, J. 1997. Effect of some environmental factors on the content and composition of microbial membrane lipids. Crit. Rev. Biotechnol. 17:87-103. https://doi.org/10.3109/07388559709146608.

Schiller, J., R. Süß, J. Arnhold, B. Fuchs, J. Leßig, M. Müller, M. Petković, H. Spalteholz, O. Zschörnig, and K. Arnold. 2004. Matrix-assisted laser desorption and ionization time-of-flight (MALDI-TOF) mass spectrometry in lipid and phospholipid research. Prog. Lipid Res. 43:449-488. https://doi.org/10.1016/j.plipres .2004.08.001.

Shu, X., M. Liang, B. Yang, Y. Li, C. Liu, Y. Wang, and J. Shu. 2012. Lipid fingerprinting of Bacillus spp. using online MALDI-TOF mass spectrometry. Anal. Methods 4:3111-3117. https://doi.org/ $10.1039 / \mathrm{c} 2 \mathrm{ay} 25579 \mathrm{k}$.

Sohlenkamp, C., and O. Geiger. 2016. Bacterial membrane lipids: Diversity in structures and pathways. FEMS Microbiol. Rev. 40:133159. https://doi.org/10.1093/femsre/fuv008.

Vieira, C. P., T. S. Álvares, L. S. Gomes, A. G. Torres, V. M. F. Paschoalin, and C. A. Conte-Junior. 2015. Kefir grains change fatty acid profile of milk during fermentation and storage. PLoS One 10:e0139910. https://doi.org/10.1371/journal.pone.0139910.

Voorhees, K. J., K. R. Jensen, C. R. McAlpin, J. C. Rees, R. Cody, M. Ubukata, and C. R. Cox. 2013. Modified MALDI MS fatty acid profiling for bacterial identification. J. Mass Spectrom. 48:850855. https://doi.org/10.1002/jms.3215.

Wang, X., S. P. Devaiah, W. Zhang, and R. Welti. 2006. Signaling functions of phosphatidic acid. Prog. Lipid Res. 45:250-278. https: //doi.org/10.1016/j.plipres.2006.01.005.

Wenk, M. R. 2005. The emerging field of lipidomics. Nat. Rev. Drug Discov. 4:594-610. https://doi.org/10.1038/nrd1776.

Wymann, M. P., and R. Schneiter. 2008. Lipid signalling in disease. Nat. Rev. Mol. Cell Biol. 9:162-176. https://doi.org/10.1038/ nrm2335.

Yener, S., and H. J. F. van Valenberg. 2019. Characterisation of triacylglycerols from bovine milk fat fractions with MALDI-TOF-MS fragmentation. Talanta 204:533-541. https://doi.org/10.1016/j .talanta.2019.06.013.

Yoon, B. K., J. A. Jackman, E. R. Valle-González, and N.-J. Cho. 2018. Antibacterial free fatty acids and monoglycerides: Biological activities, experimental testing, and therapeutic applications. Int. J. Mol. Sci. 19:1114. https://doi.org/10.3390/ijms19041114.

\section{ORCIDS}

Justyna Walczak-Skierska @ https://orcid.org/0000-0001-9038-0470 Michał Złoch @ https://orcid.org/0000-0001-6169-3099 